\title{
Nanostructured Ti surfaces and retinoic acid/ dexamethasone present a spatial framework for the maturation and amelogenesis of LS-8 cells
}

This article was published in the following Dove Press journal: International Journal of Nanomedicine

\author{
Nan Jiang ${ }^{1-3}$ \\ Lu Chen ${ }^{1-3}$ \\ Qianli $\mathrm{Ma}^{4,5}$ \\ Jianping Ruan ${ }^{1-3}$ \\ 'Department of Preventive Dentistry, \\ College of Stomatology, Xi'an \\ JiaoTong University, Xi'an, People's \\ Republic of China; ${ }^{2}$ Key Laboratory \\ of Shaanxi Province for Craniofacial \\ Precision Medicine Research, \\ College of Stomatology, Xi'an \\ JiaoTong University, Xi'an, People's \\ Republic of China; ${ }^{3}$ Clinical Research \\ Center of Shaanxi Province for \\ Dental and Maxillofacial Diseases, \\ College of Stomatology, Xi'an \\ JiaoTong University, Xi'an, People's \\ Republic of China; ${ }^{4}$ Department of \\ Immunology, School of Basic Medicine, \\ Fourth Military Medical University, \\ Xi'an, People's Republic of China; \\ ${ }^{5}$ Department of Prosthodontics, \\ College of Stomatology, Xi'an \\ JiaoTong University, Xi'an, \\ People's Republic of China
}

Purpose: To investigate the amelogenesis-inductive effects of surface structures at the nanoscale. For this purpose, variable nanostructured titanium dioxide $\left(\mathrm{TiO}_{2}\right)$ surfaces were used as a framework to regulate the amelogenic behaviors of ameloblasts with the administration of retinoic acid (RA)/dexamethasone (DEX).

Materials and methods: $\mathrm{TiO}_{2}$ nanotubular (NT) surfaces were fabricated via anodization. Mouse ameloblast-like LS-8 cells were seeded and cultured on NT surfaces in the presence or absence of RA/DEX for $48 \mathrm{~h}$. The amelogenic behaviors and extracellular matrix (ECM) mineralization of LS-8 cells on nanostructured Ti surfaces were characterized using field emission scanning electron microscope, laser scanning confocal microscope, quantitative polymerase chain reaction, MTT assay, and flow cytometry.

Results: $\mathrm{TiO}_{2}$ NT surfaces (tube size $\sim 30$ and $\sim 80 \mathrm{~nm}$ ) were constructed via anodization at 5 or $20 \mathrm{~V}$ and denoted as NT5 and NT20, respectively. LS-8 cells exhibited significantly increased spread and proliferation, and lower rates of apoptosis and necrosis on NT surfaces. The amelogenic gene expression and ECM mineralization differed significantly on the NT20 and the NT5 and polished Ti sample surfaces in standard medium. The amelogenic behaviors of LS- 8 cells were further changed by RA/DEX pretreatment, which directly drove maturation of LS-8 cells.

Conclusion: Controlling the amelogenic behaviors of ameloblast-like LS-8 cells by manipulating the nanostructure of biomaterials surfaces represents an effective tool for the establishment of a systemic framework for supporting enamel regeneration. The administration of RA/DEX is an effective approach for driving the amelogenesis and maturation of ameloblasts.

Keywords: $\mathrm{TiO}_{2}$ nanotube, LS-8, surface nanostructure, amelogenesis, retinoic acid

\section{Introduction}

Dental caries have been ranked as the most common oral condition among 291 diseases. ${ }^{1}$ A variety of factors, such as genetic disorders, microbial infections, and trauma, can lead to tooth decay and loss, which may be progressively aggravated by poor oral hygiene and negligence. ${ }^{2-4}$ Currently, dental treatments such as root canal therapy (RCT), conventional fix denture, and implant-supported denture are used to restore the affected tissues and their functionality. However, with these procedures after an RCT, teeth lose vitality and sensitivity, and become fragile over time. ${ }^{5}$ Dental implants lack periodontal ligament; therefore, masticatory stresses and homeostasis of alveolar bone are not equivalent to that of natural dentition. ${ }^{6}$ These shortcomings inspired the development of alternative methods for tooth regeneration such as the dental epithelium-mesenchymal complex, cell-tissues recombination, gene-modified 
tooth regeneration, ${ }^{6-8}$ and humanized chimeric tooth. ${ }^{9}$ Although these studies reported promising results for regeneration of tooth tissues, no mature dental enamel was formed.

As the outmost layer of the human tooth, enamel is the most highly mineralized tissue in the human body and contains the highest percentage $(>95 \%)$ of hydroxyapatite. ${ }^{10,11}$ Mature enamel does not contain any cells, blood vessels, or nerves and cannot repair or heal. ${ }^{12,13}$ It lacks an amelogenic micro-environment which provides crucial spatial structure and growth factors to support ameloblastic cellular growth and differentiation for enamel formation. ${ }^{14,15}$

Surface modifications at the nanoscale may represent a promising strategy for the construction of spatial structures that support tissue regeneration. Impressively, Dalby et al reported that slightly disordered nano-pits $(\sim 120 \mathrm{~nm}$ diameter) on polymethylmethacrylate induced osteogenic differentiation of mesenchymal stem cell (MSC). ${ }^{16}$ This observation suggests that biomaterial surface topography plays an important role in regulating various host responses. ${ }^{17,18}$ Specifically, a $\mathrm{TiO}_{2}$ nanotubular (NT) surface array facilitated osteogenic differentiation and extracellular matrix (ECM) mineralization of osteoblastic lineage cells in vitro. ${ }^{17,19,20}$ In addition, the nanostructure of the NT array closely matches the cross section of bone collagen. ${ }^{21}$ The biomimetic structure of the NT array probably contributes to the functional alternation of osteoblastic lineage cells. ${ }^{22}$ Notably, the spatial structures of the NT array mimic enamel rods. $^{23,24}$ Therefore, we hypothesized that the NT array can be used as a framework to support ameloblasts for enamel regeneration.

In the current in vitro study, titanium (Ti) samples were treated with anodization and ultraviolet $\mathrm{A} /$ ultraviolet $\mathrm{C}$ (UVA/C) irradiation to fabricate super-hydrophilic $\mathrm{TiO}_{2} \mathrm{NT}$ surfaces (NT5 and NT20) for enamel regeneration. The $\mathrm{TiO}_{2}$ NT surfaces were characterized for biological behavior to promote amelogenic differentiation of ameloblast-like cells (LS-8) on nanostructured Ti samples in standard medium or amelogenic differentiation medium. The aims of this study were to advance our understanding of the amelogenesisinductive effects of surface structures at the nanoscale. For this purpose, variable nanostructured $\mathrm{TiO}_{2}$ surfaces were used as a framework to regulate the amelogenic behaviors of ameloblasts with the administration of retinoic acid (RA)/ dexamethasone (DEX). The results obtained in this study may provide a systemic research framework for exploration and evaluation of enamel regeneration through surface nanotopography.

\section{Materials and methods Nanostructured $\mathrm{TiO}_{2}$ surface fabrication and characterization}

Nanoscale textured Ti samples were prepared using a multistep procedure. Grade 1 pure $\mathrm{Ti}(99.9 \%)$ sheets were donated by the Northwest Institute for Nonferrous Metal Research (NIN, Xi'an, People's Republic of China). Disk-shaped samples (14×1 mm) were cut from a Ti sheet by machining. Nanostructured $\mathrm{Ti}$ samples were prepared as described previously. ${ }^{25}$ In brief, samples were polished using SiC sandpaper $(1,500-8,000$ grit; Matador, Germany) and ultrasonically cleaned with acetone, ethanol, and deionized water in sequence for 15 min each. Ti samples were then anodized in an aqueous electrolyte solution containing $0.5 \mathrm{wt} \%$ hydrofluoric acid and $1 \mathrm{M}$ phosphoric acid at $20^{\circ} \mathrm{C}$ for $1 \mathrm{~h}$. A direct current power supply and a platinum cathode set at 5 or $20 \mathrm{~V}$ was used to fabricate the nanostructured, textured surfaces denoted P (polished Ti sample), NT5, and NT20, respectively. ${ }^{26}$ The topography of the prepared Ti surfaces was assessed by an atomic force microscope (AFM, Dimension Icon, Bruker AXS Inc., Madison, WI, USA) and field emission scanning electron microscopy (FE-SEM, magnification of 100,000×, S-4800; Hitachi Ltd., Tokyo, Japan). The contact angles and hydrophilicity of the samples were assessed by a Contact Angle Meter (DSA1 System, Kruss, Germany). The contact angles were measured instantly after placing a droplet of water with $10 \mu \mathrm{L}$ of each click and at an interval of 0.5 and $2.0 \mathrm{~s}$ with the Drop Shape Analysis (DSA) software. The elemental composition was analyzed by X-ray photoelectron spectroscopy (XPS, ESCALAB 250Xi; Thermo Fisher Scientific, Waltham, MA, USA). The prepared samples were sterilized by UVA/C irradiation ( $\lambda=365 \mathrm{~nm}$ (A) $/ 254 \mathrm{~nm}$ (C); Philips, Poland) at a distance of $50 \mathrm{~mm}$ for $1 \mathrm{~h}$ and then placed in wells of 24-well plates (Corning, USA) prior to cell culture.

\section{Culture of LS-8 cell line}

Mouse immortalized ameloblast-like cells (LS-8) were acquired for the experiments (USC, Los Angeles, CA, USA). The presence of Tomes' process-like structure suggests that LS-8 cells are ameloblasts in the secretory phase. ${ }^{27}$ LS-8 cells were cultured in standard DMEM (Cellgro, USA) with $4.5 \mathrm{~g} / \mathrm{L}$ glucose, $10 \%$ fetal calf serum (Thermo Fisher Scientific), and 1\% penicillin/streptomycin complex (Cellgro) at $37^{\circ} \mathrm{C}$ with $5 \% \mathrm{CO}_{2}$. The culture medium was changed every 2 days. After growing to sub-confluence, cells were digested, counted, and passaged into $75 \mathrm{~cm}^{2}$ culture flasks $\left(\sim 2 \times 10^{6}\right.$ cells/flask). The study protocol, including the use of LS- 8 cell lines, was reviewed and approved by the Medical Ethics Committee of the College 
of Stomatology, Xi'an JiaoTong University, Xi'an, People's Republic of China (approval no. xjkqll[2018] No 012).

\section{Morphological observation of LS-8 cells on nanostructured $\mathrm{TiO}_{2}$ surfaces}

LS-8 cells were seeded onto the prepared Ti samples $\left(2 \times 10^{4}\right.$ cells/well) and cultured for $24,48,72$, or $96 \mathrm{~h}$ either in standard medium (DMEM as described earlier) or amelogenic RA medium (standard medium containing $100 \mathrm{nM}$ DEX [Sigma-Aldrich Co., St Louis, MO, USA] and $20 \mathrm{ug} / \mathrm{mL}$ retinacid [RA; USA Pharmacopeia, USA]). For laser scanning confocal microscopy (LSCM), samples were fixed in 4\% paraformaldehyde and stained using rhodamine-labeled phalloidin $(1 \mu \mathrm{g} /$ $\mathrm{mL}$; Sigma-Aldrich) and 4',6-diamidino-2-phenylindole (DAPI, $1 \mu \mathrm{g} / \mathrm{mL}$; Hoffman-La Roche Ltd., Basel, Switzerland). After glycerol mounting, samples were observed by LSCM (FV1200; Olympus Corporation, Tokyo, Japan). LS-8 cell number and morphology were analyzed using Image ProPlus (Media Cybernetics, USA), with a scale bar of $50 \mu \mathrm{m}$.

\section{LS-8 proliferation on different Ti surfaces}

LS- 8 cells were seeded onto the prepared Ti samples $\left(2 \times 10^{4}\right.$ cells/well) and cultured in a 24-well culture plate for 24,48 , 72 , or $96 \mathrm{~h}$ in standard culture or RA medium. Proliferation of LS-8 cells was assessed by MTT assay as detailed previously. ${ }^{26}$ Briefly, at the prescribed time points, the samples were rinsed thrice in PBS (Cellgro) and transferred to new 24-well culture plates. To each well was added $200 \mu \mathrm{L}$ MTT-PBS solution (Amresco, USA), $800 \mu \mathrm{L}$ serum- and phenol red-free DMEM, and the samples were incubated at $37^{\circ} \mathrm{C}$ for $4 \mathrm{~h}$ to allow formazen formation. The formazen was then dissolved with DMSO (1 mL/well; MP Biomedicals, USA). Optical density was measured at $490 \mathrm{~nm}$ (570 nm as reference) on a spectrophotometer (Biotek, USA).

\section{Apoptosis and necrosis of LS-8 cells on different Ti surfaces}

LS- 8 cells were seeded on Ti samples at $1 \times 10^{5}$ cells/well and cultured for $24 \mathrm{~h}$ to allow cell attachment. Ti samples were then cultured in standard or RA medium for $48 \mathrm{~h}$. LS-8 cells on prepared Ti surfaces were resuspended using $0.25 \%$ trypsin (Cellgro). The apoptosis/necrosis of LS-8 cells was assessed using the Annexin V/propidium iodide (PI) kit (Seven Seas, People's Republic of China) as described by the manufacturer. Using the FACS Aria II system (BD Biosciences, San Jose, CA, USA), Annexin $\mathrm{V}^{-} / \mathrm{PI}^{-}$cells were considered viable, annexin $\mathrm{V}^{+} / \mathrm{PI}^{-}$cells were considered apoptotic cells, and Annexin $\mathrm{V}^{+} / \mathrm{PI}^{+}$cells were considered necrotic. Quantitative polymerase chain reaction (qPCR) was used to detect the expression of the apoptosis-related genes B-cell lymphoma-2 (BCL-2); BCL2-associated X protein $(B A X)$; and caspase 3 (CASP3). Total RNA was isolated from cells using the RNAiso Plus system (Takara, Japan). Aliquots of $1 \mu \mathrm{g}$ total RNA were translated to cDNA using the PrimeScript ${ }^{\mathrm{TM}} \mathrm{RT}$ reagent kit (Takara). qPCR was conducted using FastStart Universal SYBER Green Master (Hoffman-La Roche Ltd.) on a CFX96 ${ }^{\mathrm{TM}}$ PCR System (Bio-Rad Laboratories Inc., Hercules, CA, USA). Glyceraldehyde 3-phosphate dehydrogenase (GAPDH) was used as a housekeeping gene. The primers used are listed in Table 1.

Table I Primers used for real-time PCR

\begin{tabular}{|c|c|c|c|c|}
\hline Gene & Accession number & Forward primer sequence $\left(5^{\prime}-3^{\prime}\right)$ & Reverse primer sequence $\left(5^{\prime}-3^{\prime}\right)$ & $\begin{array}{l}\text { Product } \\
\text { size (bp) }\end{array}$ \\
\hline BMP2 & NM_007553.3 & TGACTGGATCGTGGCACCTC & CAGAGTCTGCACTATGGCATGGTTA & 112 \\
\hline RUNX2 & NM_00I27I627.I & TGCAAGCAGTATTTACAACAGAGG & GGCTCACGTCGCTCATCTT & 188 \\
\hline SHH & NM_009170.3 & GTTTATTCCCAACGTAGCCGAGA & CAGAGATGGCCAAGGCATTTA & 200 \\
\hline AMELX & NM_009666.4 & GATGGCTGCACCACCAAATC & CTGAAGGGTGTGACTCGGG & 65 \\
\hline$A M B N$ & NM_00I30343I.I & ACTGCTACCTGGAAACAA & TGCGGAAGGATAGTAAGT & 161 \\
\hline ENAM & NM_0I7468.3 & TGCAGAAATCCGACTTCTCCT & CATCTGGAATGGCATGGCA & 114 \\
\hline KLK4 & NM_019928.I & CCGGATCATACAAGGCCAGG & TGCGGATGCACCAAGACTC & 105 \\
\hline MMP-20 & NM_013903.2 & ACACATTTCGACAATGCTGAGA & AAGTTGGGTACATCAGTGCTG & 136 \\
\hline AMTN & NM_027793.I & GCACATACTCTCCCGTTCAC & AAGATTTGGGAGGCTAACGG & 144 \\
\hline ODAM & NM_027I28.2 & TTGACAGCTTTGTAGGCACA & GACCTTCTGTTCTGGAGCAA & 197 \\
\hline$B C L-2$ & NM_00974I.5 & TGTCACAGAGGGGCTACGAGT & TCAGGCTGGAAGGAGAAGATG & 94 \\
\hline$B A X$ & NM_007527.3 & CCAGGATGCGTCCACCAA & AAAGTAGAAGAGGGCAACCAC & 196 \\
\hline CASP3 & NM_001284409.I & СTAATCTGACGGTCCTCC & TCGCCAAATCTTGCTAAT & 200 \\
\hline GAPDH & NM_00I289726.I & CATGTTCCAGTATGACTCCACTC & GGCCTCACCCCATTTGATGT & 136 \\
\hline
\end{tabular}

Abbreviations: BMP-2, bone morphogenetic protein-2; RUNX2, runt-related transcription factor 2; SHH, sonic hedgehog; $A M E L X$, amelogenin X-linked; $A M B N$, ameloblastin; ENAM, enamelin; KLK4, kallikrein related-peptidase 4; MMP-20, matrix metallopeptidase 20; AMTN, amelotin; ODAM, odontogenic, ameloblast-associated protein; BCL-2, B-cell lymphoma-2; BAX, BCL2-associated X protein; CASP3, caspase-3; GAPDH, glyceraldehyde-3-phosphate dehydrogenase. 


\section{Amelogenic gene expression of LS-8 cells on different Ti surfaces}

We used qPCR to detect the expression of enamel formationrelated genes, such as bone morphogenetic protein-2 (BMP-2), runt-related transcription factor 2 (RUNX2), sonic hedgehog $(S H H)$, amelogenin X-linked (AMELX), ameloblastin $(A M B N)$, enamelin $(E N A M)$, kallikrein relatedpeptidase $4(K L K-4)$, matrix metallopeptidase $20(M M P-20)$, amelotin $(A M T N)$, and odontogenic ameloblast-associated protein $(O D A M)$. As described in Apoptosis and necrosis of LS-8 cells on different Ti surfaces section, cells were seeded on Ti samples at a concentration of $1 \times 10^{5}$ cells/well and cultured for $24 \mathrm{~h}$. Then, half of the Ti samples were cultured in standard medium for 3 or 7 days, whereas the other half of the Ti samples were treated with RA medium for $48 \mathrm{~h}$; this was followed by culturing with standard medium for an additional 1 or 5 days ( 3 or 7 days of culture, in total). The total RNA was isolated and translated to cDNA. qPCR was undertaken with $G A P D H$ as a housekeeping gene.

\section{ECM mineralization of LS-8 cells on different Ti surfaces}

As described in Apoptosis and necrosis of LS-8 cells on different Ti surfaces section, cells were seeded on Ti samples at a concentration of $1 \times 10^{5}$ cells/well and cultured for $24 \mathrm{~h}$. Then, half of the Ti samples were cultured in standard medium for 7 or 28 days, and the other half of Ti samples were treated with RA medium for $48 \mathrm{~h}$ and then cultured in standard medium for an additional 5 or 26 days (7 or 28 days of culture, in total). Samples cultured for 7 days were fixed in $4 \%$ paraformaldehyde and stained with the alkaline phosphatase (ALP) staining kit (Sigma-Aldrich) according to the manufacturer's instructions. Samples cultured for 28 days were fixed in $60 \%$ isopropanol for $1 \mathrm{~min}$. After rehydration in distilled water for $3 \mathrm{~min}$, cells were stained with $1 \mathrm{wt} \%$ alizarin red S (Sigma-Aldrich) for $3 \mathrm{~min}$ at room temperature. Images were taken by a stereoscopic microscope (Leica Microsystems, Wetzlar, Germany). To quantify the red-stained mineralized nodules, the stain was solubilized within $10 \%$ cetylpyridinum chloride in $10 \mathrm{mM}$ sodium phosphate, and absorbance values were measured at $620 \mathrm{~nm}$ using a spectrophotometer (Biotek) and with a protocol similar to that used for the MTT assay.

\section{Statistical analysis}

Experiments were repeated three times, with four replicates in each group. All data were analyzed using SPSS 19.0 (IBM Corporation, Armonk, NY, USA) and are expressed as mean \pm $\mathrm{SD}$ (for data fitting normal distribution) or mean (for data not fitting normal distribution) for continuous variables. Significant differences between groups were identified using one-way analysis of variance (ANOVA) followed by Student-NewmanKeuls post hoc test for parametric data (expressed as bar charts with mean values and error bars) or Kruskal-Wallis test followed by Dunn's multiple comparison test for non-parametric data (expressed in scatter plots with mean values). Differences were considered statistically significant when $p<0.01$.

\section{Results \\ Surface characterization of $\mathrm{TiO}_{2}$ - nanostructured surfaces on Ti samples}

The surface topography of the prepared samples (P, NT5, and NT20) was visualized by AFM and FE-SEM from a vertical and a lateral view (Figure $1 \mathrm{~A}$ and $\mathrm{B}$ ). As a result of anodization at 5 and $20 \mathrm{~V}$, uniformly distributed NT structures with tube size of $\sim 30$ and $\sim 80 \mathrm{~nm}$ and tube lengths of $\sim 100 \mathrm{~nm}$ (NT5) and $650 \mathrm{~nm}$ (NT20) were formed on Ti samples. In contrast, the $\mathrm{P}$ exhibited a smooth surface. The roughness of nanostructured Ti surfaces was measured by AFM. Anodization increased the roughness significantly, and the roughness of all samples was gradually increased as a factor of anodization voltage (Table 2). Surface elements were analyzed by XPS. The relative atomic concentrations of Ti, O, and C, and the Ti:O ratios were similar on P, NT5, and NT20 surfaces (Table 3; Figure S1).

Based on contact-angle measurements (instant, $0.5 \mathrm{~s}$, and 2.0 s post-contact), the hydrophilicities of NT5 and NT20 were similar and were both significantly higher $(p<0.01)$ than that of the $\mathrm{P}$ surfaces (Figure $1 \mathrm{C}$ and $\mathrm{D}$ ). The instant contact angles for NT5 $\left(9.94^{\circ} \pm 1.72^{\circ}\right)$ and NT20 $\left(9.04^{\circ} \pm 2.58^{\circ}\right)$ were significantly lower $(p<0.01)$ than that of $\mathrm{P}$ surfaces $\left(44.11^{\circ} \pm 4.19^{\circ}\right.$, Figure 1D). The contact angles for NT5 and NT20 were significantly reduced to $1.16^{\circ} \pm 0.23^{\circ}$ and $1.28^{\circ} \pm 0.37^{\circ}$, respectively, within $2 \mathrm{~s}$.

\section{Morphological of LS-8 cells on nanostructured $\mathrm{TiO}_{2}$ surfaces}

The morphology of LS-8 cells on modified Ti samples was investigated via F-actin/DAPI staining and semi-quantitative image analysis. LS-8 cell morphology differed remarkably between surfaces with a different topography (Figures 2 and S2). In standard medium, compared to P surfaces, NT5 and NT20 enhanced the spread and the number of cells at all time points. Cells on NT5 and NT20 showed plenty of pseudopods compared to smooth edge on P surfaces (Figure S2). In addition, cell confluence was observed earlier in NT5 and NT20 samples (72 h) than in P surfaces, where it was achieved at 96 $\mathrm{h}$ (Figure 2A). These findings are supported by cell counting 
A
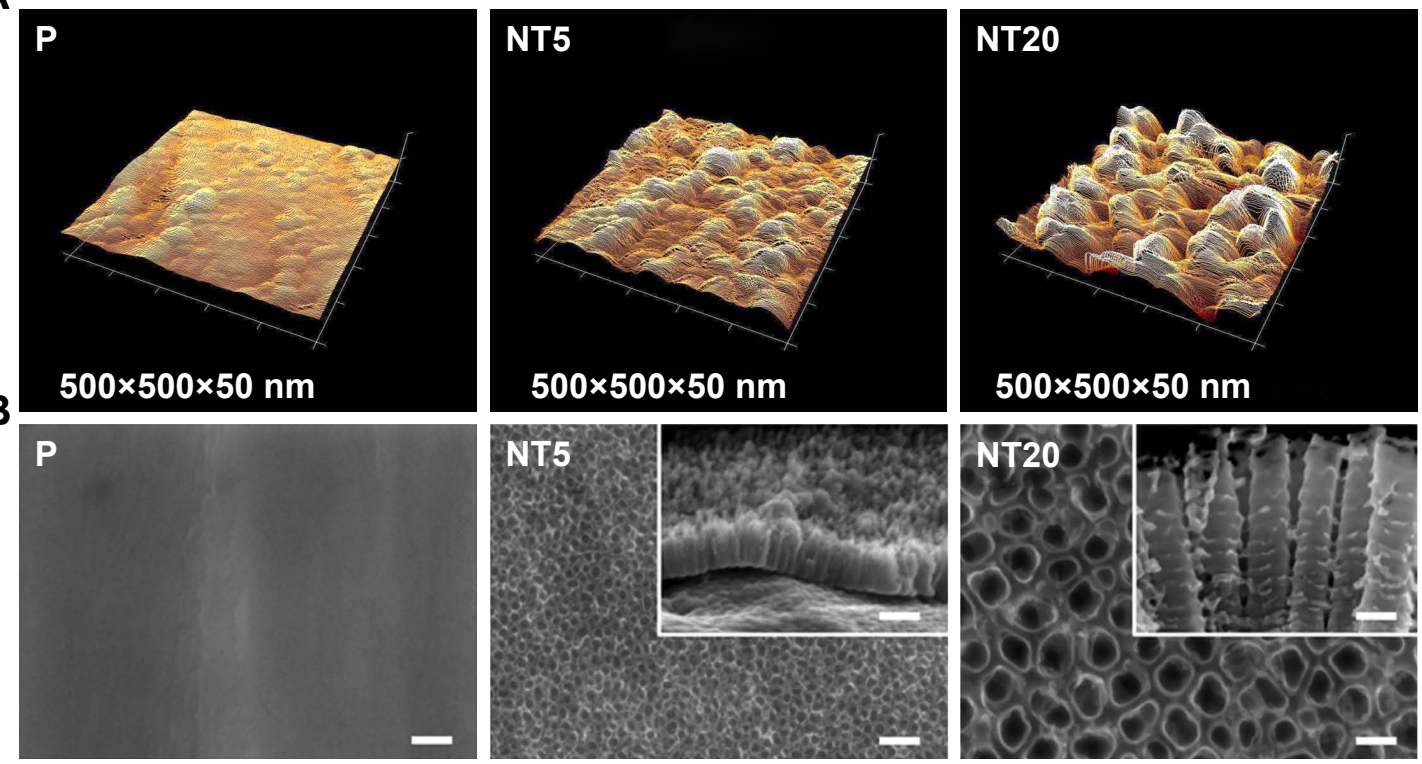

C

Instant
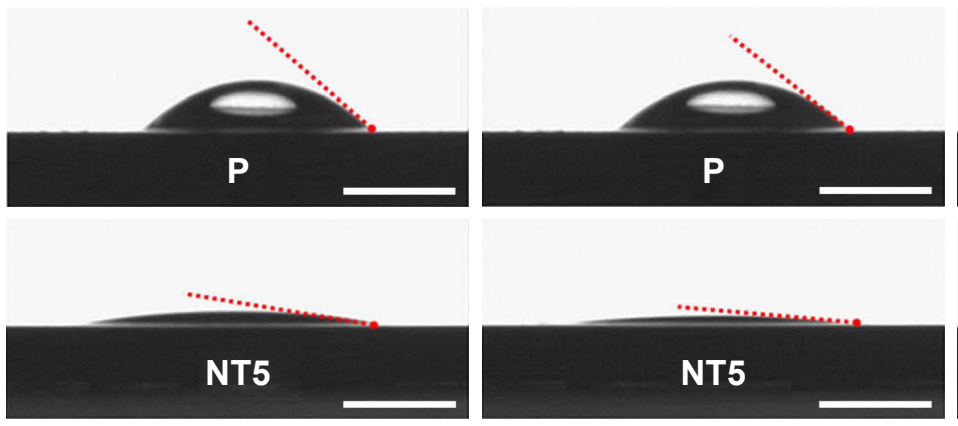

$0.5 \mathrm{~s}$ post contact
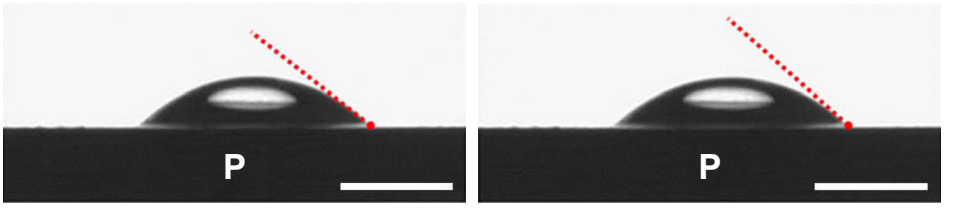

2.0 s post contact

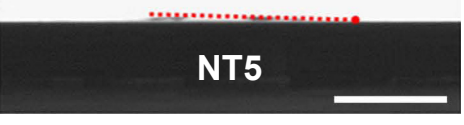

\section{NT20}
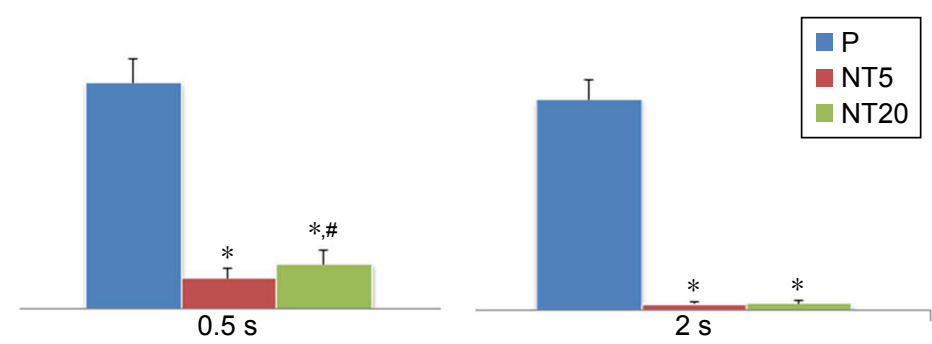

Figure I Surface characterization of nanostructured Ti surfaces.

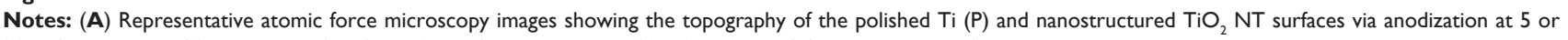
$20 \mathrm{~V}$ (NT5 and NT20, respectively) $\mathrm{TiO}_{2}$ surfaces. Scanning range $=500 \times 500 \times 50 \mathrm{~nm}$. (B) Representative field emission scanning electron microscopy images showing the morphology and topography of P, NT5, and NT20 surfaces from the vertical and lateral views (insets). Magnification=100,000x; scale bar=100 nm. (C) Representative images showing the water contact angle on modified Ti surfaces. Scale bar $=1 \mathrm{~mm}$; (D) contact angle analysis. ${ }^{*} p<0.01$ vs $P ;{ }^{*} p<0.01$ vs NT5.

Abbreviation: NT, nanotubular.

analysis (Figure 2B). Cell numbers were significantly lower on P surfaces than on NT5 and NT20 regardless of culturing time $(p<0.01)$, whereas, the number of cells in the NT5 and NT20 groups did not differ significantly after $24 \mathrm{~h}$.
In RA medium, significantly fewer cells were observed in all groups (Figure 2C). However, slightly more cells were observed on NT5 and NT20 surfaces than on P surfaces (Figure 2C and D). This difference in cell number was not 
Table 2 Surface roughness of nanostructured Ti surfaces

\begin{tabular}{lll}
\hline Group & $\mathbf{R a}(\mathbf{n m})$ & $\mathbf{R q}(\mathbf{n m})$ \\
\hline P & $1.85 \pm 0.47$ & $2.62 \pm 0.89$ \\
NT5 & $4.85 \pm 0.93^{*}$ & $6.20 \pm 1.72^{*}$ \\
NT20 & $11.40 \pm 3.05^{*, \#}$ & $14.80 \pm 2.47^{* \#}$ \\
\hline
\end{tabular}

Note: ${ }^{*} p<0.01$ vs $P ;{ }^{*} p<0.01$ vs NT5.

Abbreviations: $\mathrm{Ra}$, average roughness; $\mathrm{Rq}$, root mean square roughness.

observed at $24 \mathrm{~h}$ in the RA medium. At $48 \mathrm{~h}$, the number of cells on NT5 and NT20 surfaces was similar, but significantly higher than on $\mathrm{P}$ surfaces $(p<0.01)$. At 72 and $96 \mathrm{~h}$, the number of cells on NT20 surfaces was significantly higher than all other samples ( $p<0.01$; Figure 2D). Notably, fewer pseudopods with smooth edges were observed on all prepared Ti surfaces in the RA medium than in standard medium (Figure S2A and B).

\section{LS-8 cellular proliferation on different Ti surfaces}

The proliferation of LS-8 cells on modified Ti surfaces was assessed by measuring the relative absorbance of media at 490/570 nm (MTT assay). In the standard medium, the absorbance of all samples was gradually increased as a factor of time, and NT5 and NT20 showed significantly higher $(p<0.01)$ absorbance than the P surfaces (Figure 3A). In RA medium, the absorbance of all Ti surfaces was remarkably lower at any time than in the standard medium (Figure 3B). The absorbance data suggested that RA medium reduced cell proliferation. NT20 significantly promoted proliferation of LS-8 cells $(p<0.01)$ in both media compared to NT5 and P (Figure $3 \mathrm{~A}$ and B).

\section{Apoptosis/necrosis of LS-8 cells on different Ti surfaces}

The apoptosis/necrosis of LS-8 cells was assessed by flow cytometry after staining with Annexin V/PI. In standard medium, NT20 significantly increased the proportion of viable cells $(>70 \%)$ but reduced the fraction of necrotic cells to $\sim 16.5 \%$ (Figure 4). Cells incubated on NT5 and P surfaces displayed similar trends (Figure 4B). The RA medium directly reduced cell viability and induced accumulation of cellular debris on all groups of Ti surfaces (Figure 4B). Nevertheless, cells incubated with NT20 were more viable in the presence of RA medium.

To clarify the role of the surface nanostructure and RA medium in apoptosis, the expression of apoptosis-related genes $B A X, B C L-2$, and $C A S P 3$ mRNA was measured. However, the surface nanostructure did not appear to affect apoptosis or necrosis of LS-8 cells in either media because expressions of $B A X, B C L-2$, and $C A S P 3$ mRNA were not affected by NT5 and NT20 conditions (even between the Ti surface and culture plate), but only by RA stimulation (Figure S3).

\section{Amelogenic gene expression in LS-8 cells on different $\mathrm{Ti}$ surfaces}

The expression of amelogenic genes in various cultures were analyzed by qPCR (Figures 5 and 6). BMP-2 and $S H H$ expression was enhanced on nanostructured Ti surfaces both in the presence/absence of RA medium pretreatment. (Figures $5 \mathrm{~A}$ and $\mathrm{C}$ and $6 \mathrm{~A}$ and $\mathrm{C}$ ). RUNX2, KLK4, and $O D A M$ expression did not differ between all prepared $\mathrm{Ti}$ surfaces in standard medium but was dramatically elevated on NT5 and NT20 under RA medium stimulation (Figures 5B, $\mathrm{G}$, I and 6B, G, I). The expression of BMP-2, SHH, AMELX, $A M B N, E N A M$, and $M M P-20$ was significantly enhanced on NT5 and NT20 surfaces in the standard medium. However, such regulative effects were weakened or even reversed under the stimulation of RA medium (Figures 5A, C-F, H and 6A, $\mathrm{C}-\mathrm{F}, \mathrm{H}$ ). AMTN expression was extremely low ( $>40$ cycles) on all prepared Ti surfaces (Figure S4B and C). Besides, RA medium pretreatment suppressed the expression of $B M P-2$, $A M E L X, A M B N, E N A M$, and MMP-20, but enhanced the expression of RUNX2, SHH, KLK4, and ODAM on polished Ti surfaces (Figure S4A).

\section{ECM mineralization of LS-8 cells on different Ti surfaces}

The ECM mineralization of LS-8 cells on modified surfaces with/without RA medium was evaluated by staining of ALP

Table 3 Elements composition of nanostructured Ti surfaces

\begin{tabular}{lllll}
\hline Group & \multicolumn{2}{l}{ Relative atomic concentration (\%) } & Ti:O ratio \\
\cline { 2 - 4 } & Ti2p & Ols & Cls & $2.47 \pm 0.27$ \\
\hline P & $25.41 \pm 1.47$ & $63.07 \pm 2.63$ & $9.27 \pm 0.28$ & $2.59 \pm 0.4 I$ (ns) \\
NT5 & $24.85 \pm 2.93$ (ns) & $64.54 \pm I .23$ (ns) & $8.68 \pm 0.52$ (ns) & $2.68 \pm 0.31$ (ns) \\
NT20 & $23.40 \pm I .05$ (ns) & $62.91 \pm I .73$ (ns) & $11.26 \pm I .4 I$ (ns) & \\
\hline
\end{tabular}

Note: ns, no significance vs P or NT5. 
A

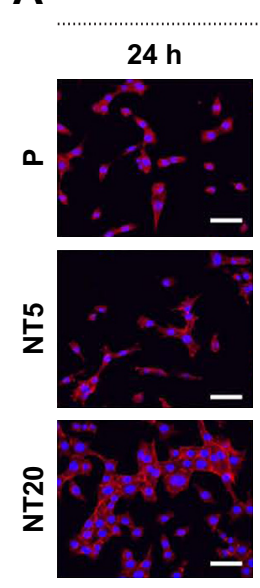

C

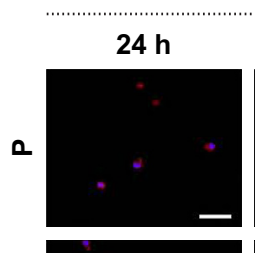

Standard medium

$48 \mathrm{~h}$
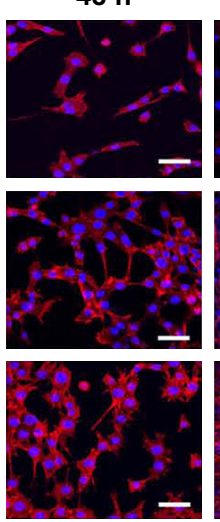

RA medium
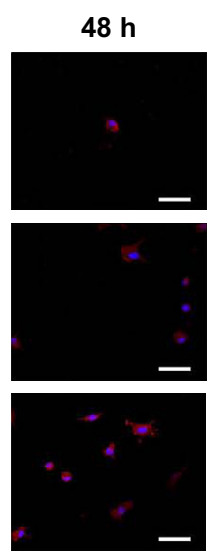

$72 \mathrm{~h}$

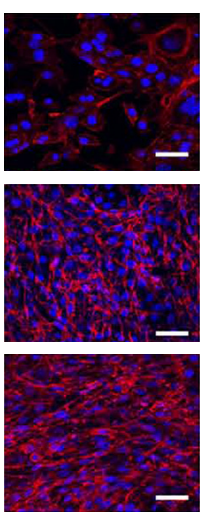

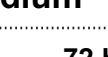
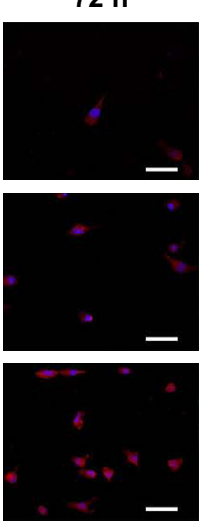

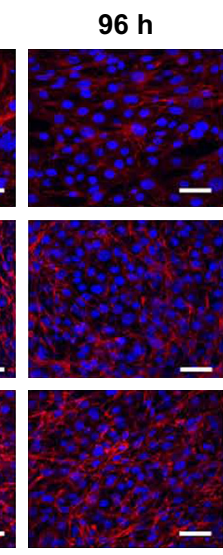

-
B

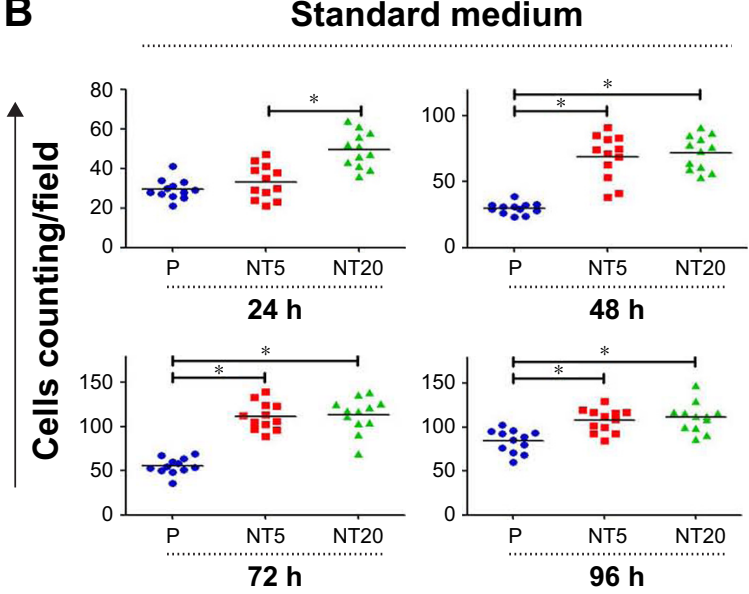

D

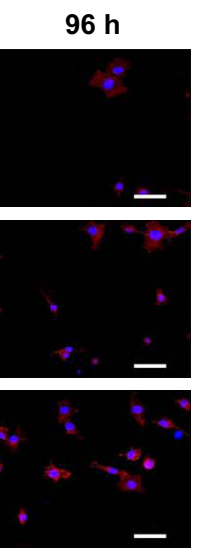

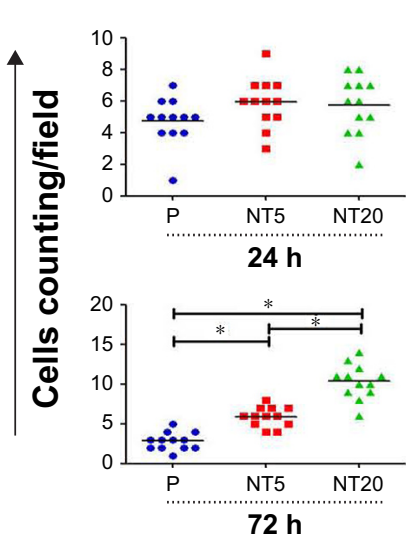

RA medium

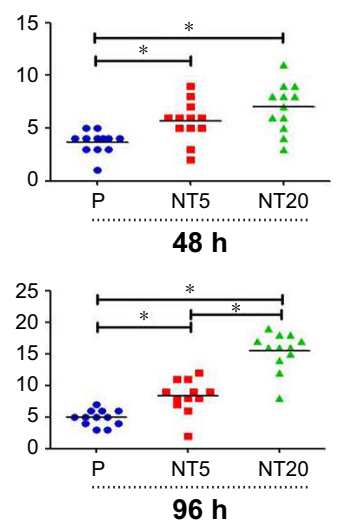

Figure 2 Morphology of LS-8 cell attachment on nanostructured Ti surfaces in standard or retinoic acid (RA) medium.

Notes: (A and C) Representative images showing the morphology of LS-8 cells attached to the prepared Ti surfaces in standard or RA medium. Magnification=400×; scale bar $=50 \mu \mathrm{m}$. (B and D) Image semi-quantitative analysis of attached LS-8 cells in standard or RA medium. ${ }^{*} p<0.01$.

and mineralized nodules. In the absence of RA medium, modified Ti surfaces (NT5 and NT20) slightly promoted ALP synthesis compared to P (Figure 7A). In contrast, in RA medium, ALP synthesis was improved on NT5 and NT20, whereas no obvious enhancement of ALP production was observed on P surfaces. ECM mineralization was increased on both NT5 and NT20 in standard medium and was further enhanced on NT surfaces in the presence of RA medium (Figure 7B). In addition, mineralized nodule formation was not increased on $\mathrm{P}$ surfaces following the addition of RA
A

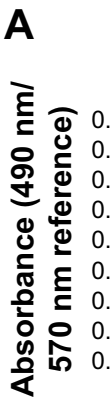

LS-8 proliferation (standard medium)

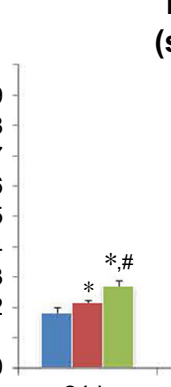

$24 \mathrm{~h}$

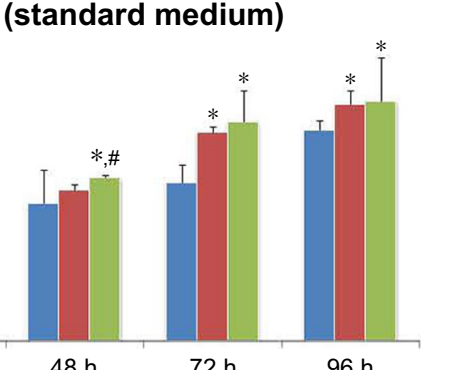

B

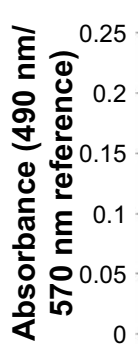

LS-8 proliferation (RA stimulation)

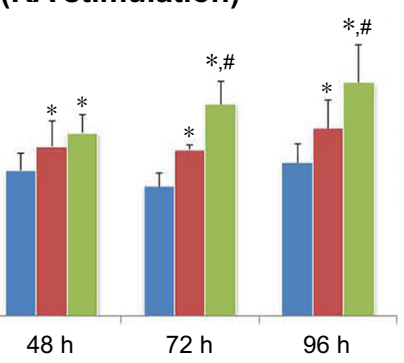

Figure 3 Proliferation of LS-8 cells cultured on nanostructured Ti surfaces in standard medium $(\mathbf{A})$ or RA medium $(\mathbf{B}) .{ }^{*} p<0.0$ I vs $P$; ${ }^{*} p<0.0$ I vs NT5. Abbreviation: RA, retinoic acid. 
A
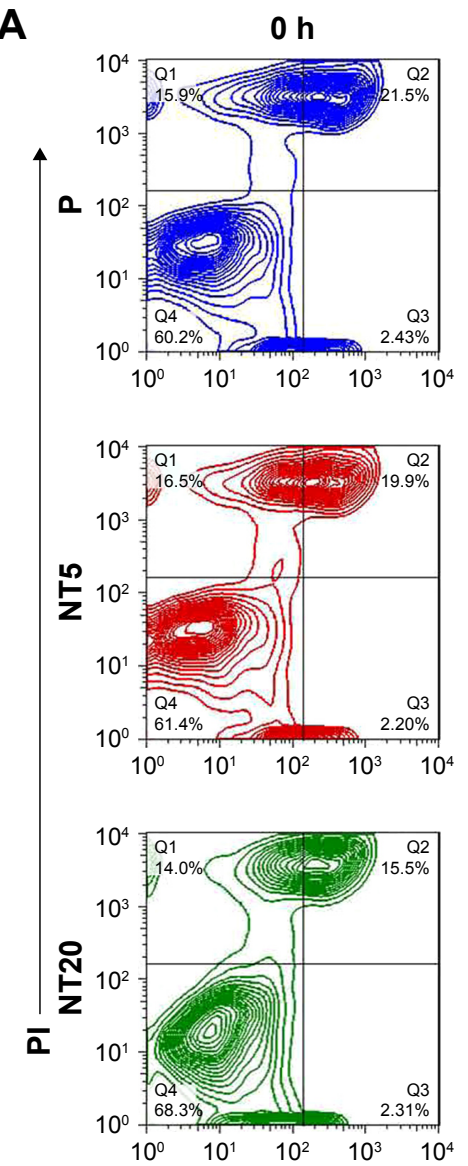

Annexin V
B
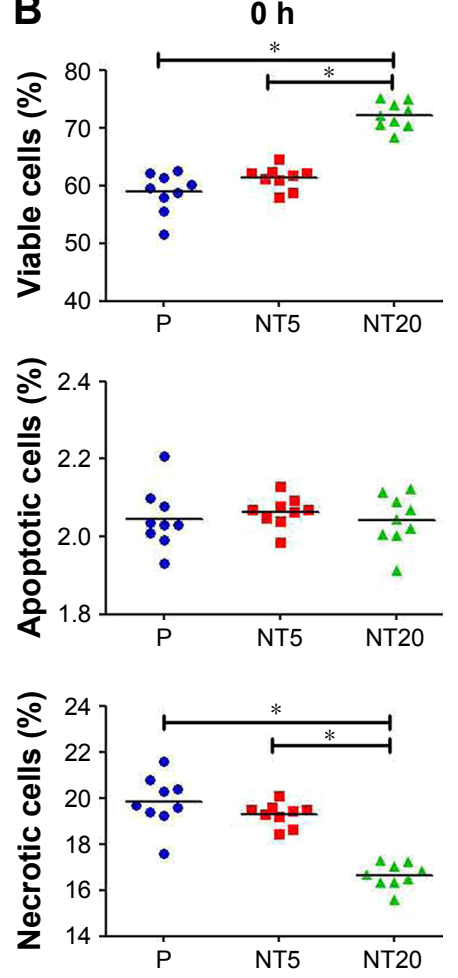

48 h-standard
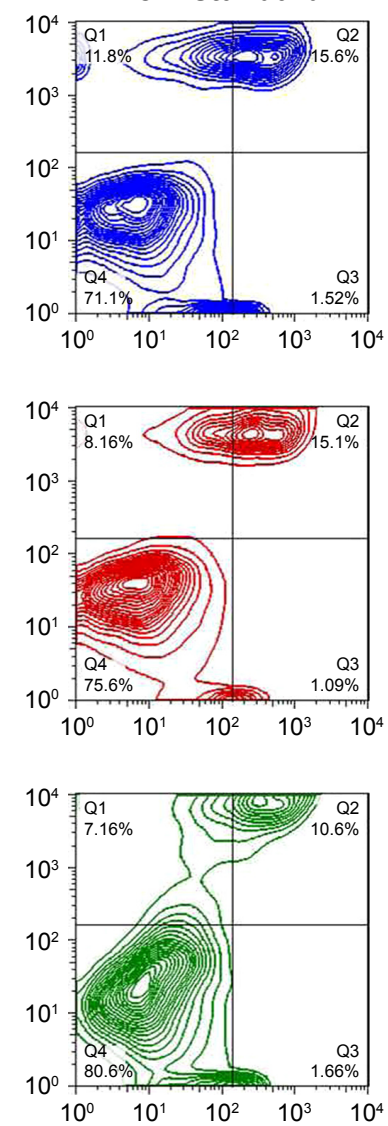

$48 \mathrm{~h}-\mathrm{RA}$
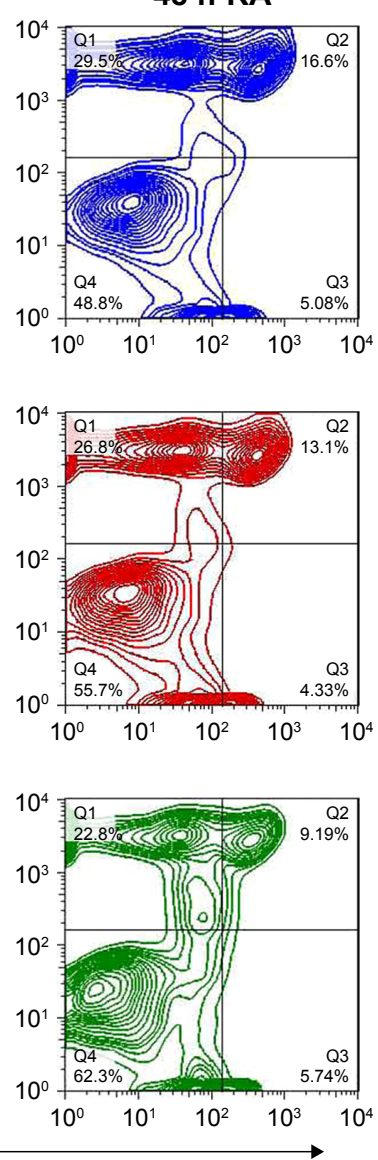

48 h-standard
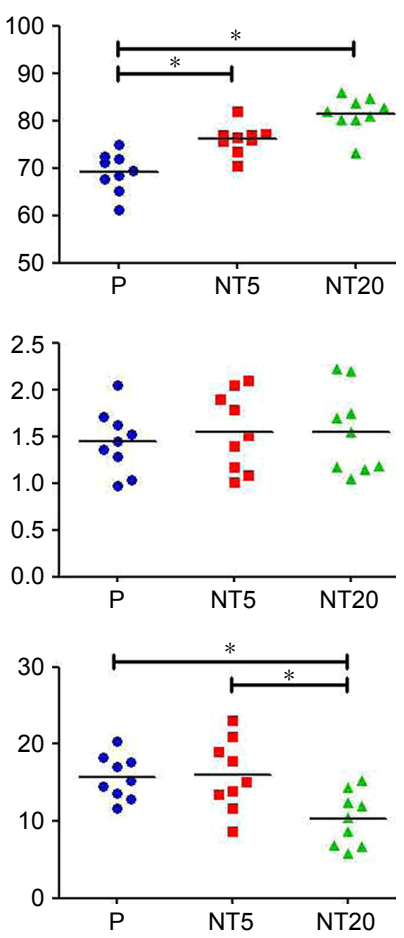

$48 \mathrm{~h}-\mathrm{RA}$
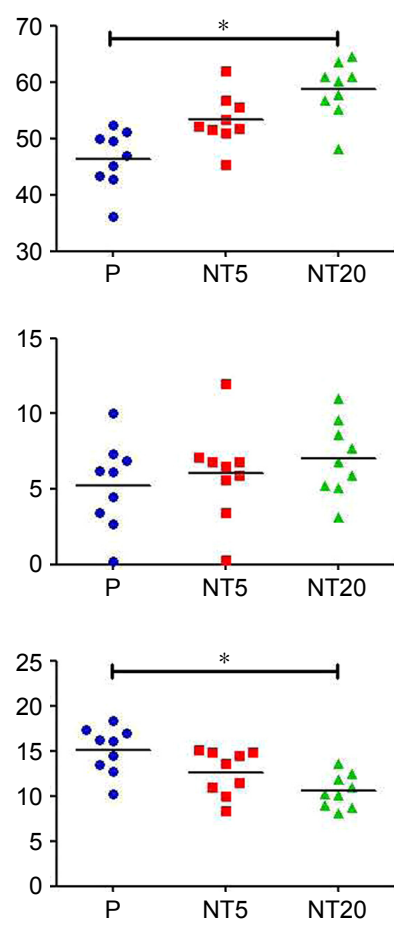

Figure 4 Apoptosis/necrosis of LS-8 cell on nanostructured Ti surfaces in standard or RA media.

Notes: (A) Representative images of flow cytometry; (B) analysis of the proportion of viable cells (upper row), apoptotic cells (middle row), and necrotic cells (lower row). ${ }^{p} p<0.01$.

Abbreviation: RA, retinoic acid. 
A

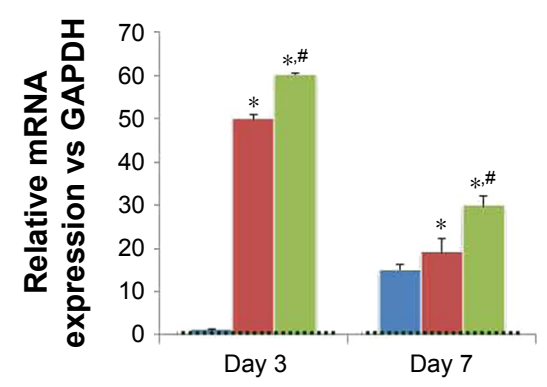

D

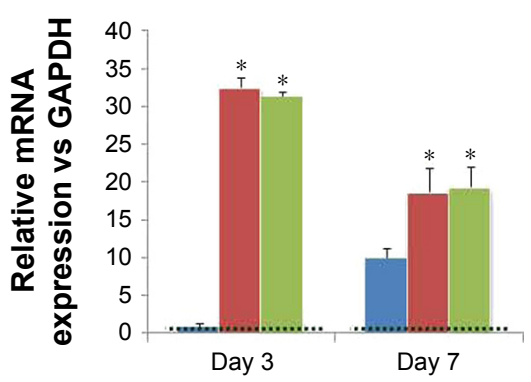

G

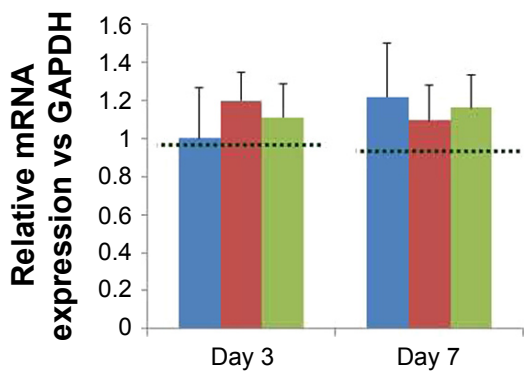

B

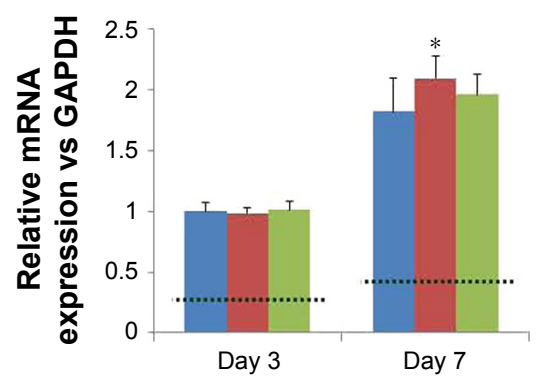

E

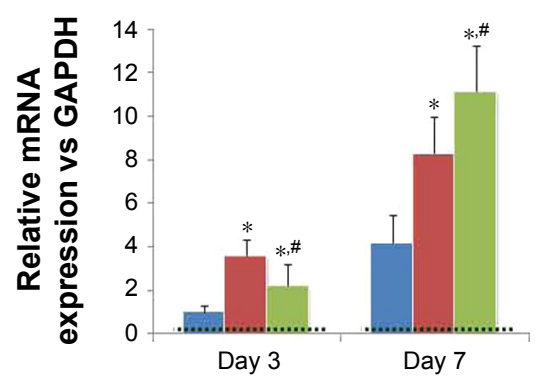

H

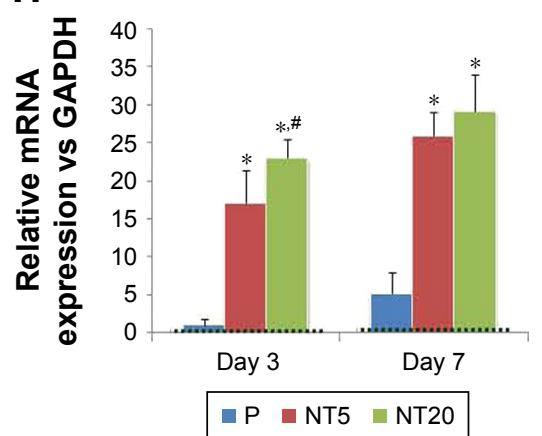

C

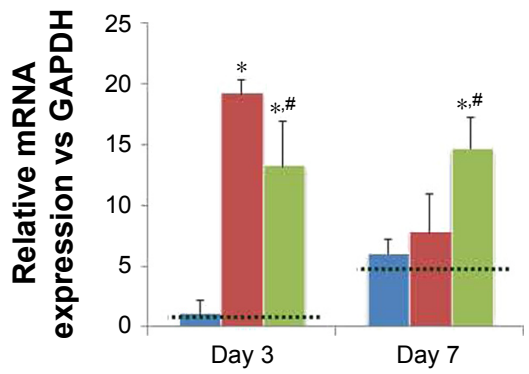

F

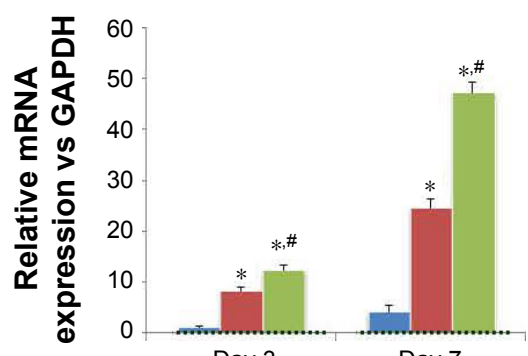

Day $3 \quad$ Day 7

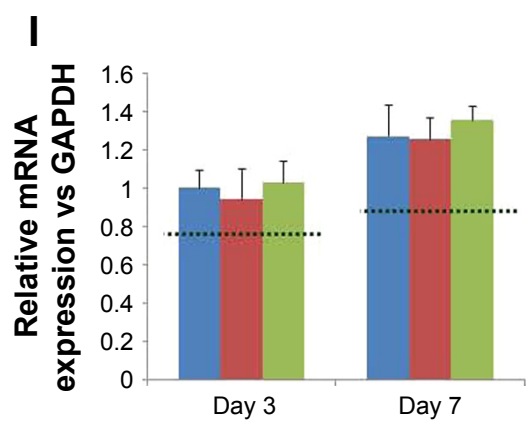

Figure 5 Expression of amelogenic genes in LS-8 cells cultured on nanostructured Ti surfaces in standard culture medium.

Notes: (A) BMP-2, (B) RUNX2, (C) SHH, (D) AMELX, (E) AMBN, (F) ENAM, (G) KLK4, (H) MMP-20, and (I) ODAM. *p<0.0I vs P; \#p<0.0I vs NT5. Dotted line, gene expression of LS-8 cells on culture plate.

medium. Conclusively, the highest ECM mineralization was obtained on NT20 in RA medium, which remained significantly higher $(p<0.01)$ than on any other surface (Figure 7C).

\section{Discussion}

This study was conducted to assess the effects of nanoscale $\mathrm{TiO}_{2}$ surfaces on amelogenesis and study the amelogenic behaviors of ameloblasts stimulated by RA and DEX. The behavior and amelogenic differentiation of ameloblastlike cells (LS-8) on nanostructured $\mathrm{TiO}_{2}$ NT surfaces was characterized using various techniques. In addition to the LS-8 cell line, the ameloblast-lineage cell line (ALC) is also widely used. Sarkar et al compared the expression profiles of LS- 8 and ALC cells and found that LS- 8 cells expressed greater levels of genes that define secretory-stage activities ( $A M E L X, A M B N, E N A M$, and MMP20), whereas ALC expresses greater levels of genes that define maturationstage activities (ODAM and $K L K 4$ ). In addition, no $A M T N$ expression was noted in either ameloblast-like cell line. ${ }^{28}$ Therefore, we chose LS- 8 cells in this study to investigate whether the amelogenic differentiation and maturation of LS-8 cells can be manipulated by surface nanostructure and RA/DEX medication. It is well known that cells are sensitive to surface features and may respond selectively to the surface topography of biomaterials. ${ }^{29-31}$ We fabricated NT surfaces that share similar chemical composition, protein adsorption, and dramatically high hydrophilicity (from instant to $2.0 \mathrm{~s}$ after water contact), but featured nanostructures of different scales. ${ }^{25,32}$ Nanoscale modifications increase the surface area 
A

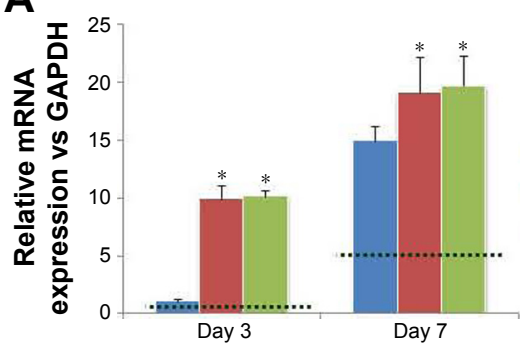

D
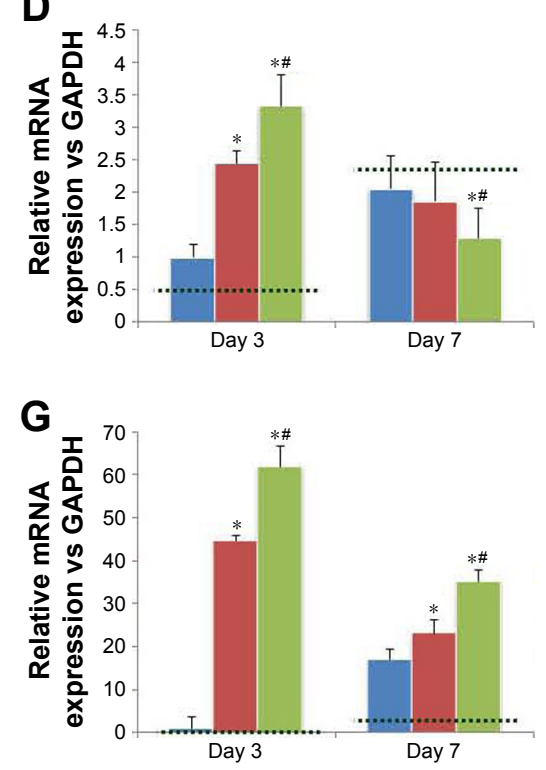

B

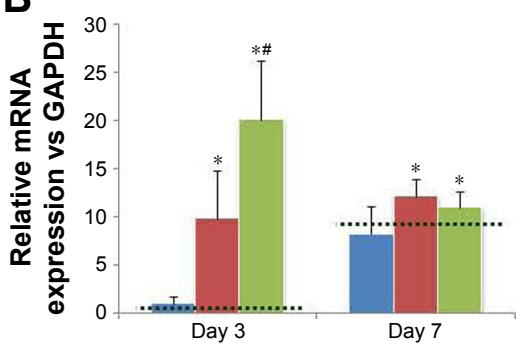

E

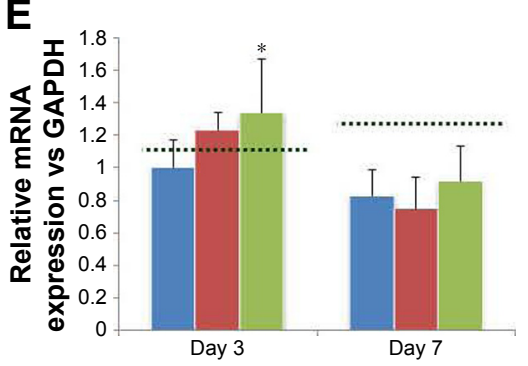

H

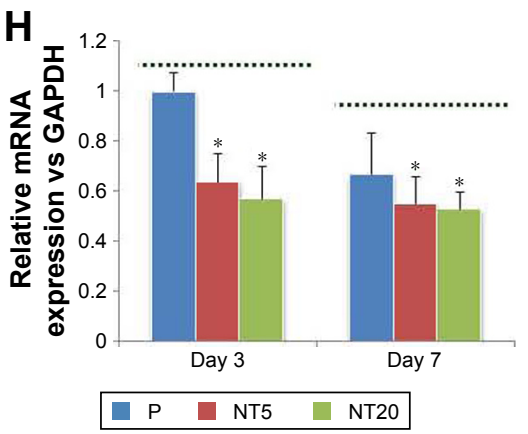

C

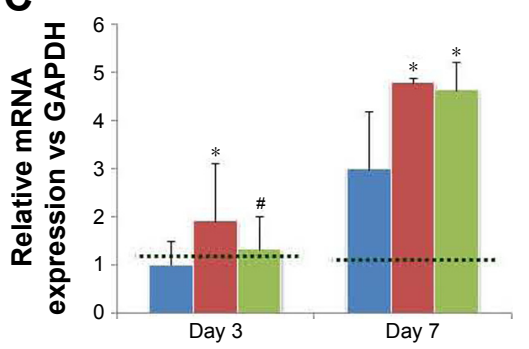

$\mathbf{F}$
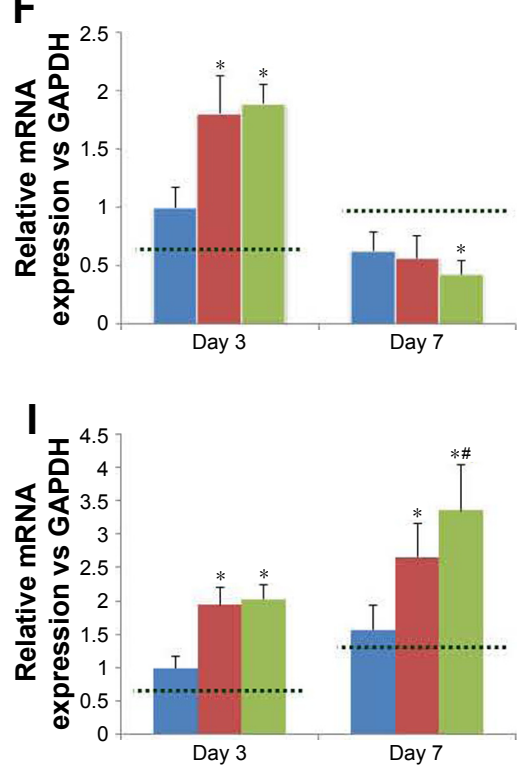

Figure 6 Expression of amelogenic genes in LS-8 cells cultured on nanostructured Ti surfaces with RA medium pretreatment.

Notes: (A) BMP-2, (B) RUNX2, (C) SHH, (D) AMELX, (E) AMBN, (F) ENAM, (G) KLK4, (H) MMP-20, and (I) ODAM. * $p<0.0$ I vs P; ${ }^{*} p<0.0$ I vs NT5. Dotted lines, gene expression of LS-8 cells on culture plate.

Abbreviation: RA, retinoic acid.

and energy that are likely to enhance cellular interactions and protein absorption. ${ }^{33,34}$ In addition, surface nanostructures could alter the focal adhesion and cytoskeleton reorganization of cells, including osteoblasts, fibroblasts, and various stem cells. ${ }^{35,36}$ Such morphologic alterations mediated by surface nanostructures are linked to the functional status of various kinds of cells, ${ }^{37-41}$ particularly osteogenic differentiation and mineralization behaviors of bone mesenchymal stem cells (bMSCs). ${ }^{37,42,43}$ To exclude the influence of the crystal phase of $\mathrm{TiO}_{2}$ on cellular responses, ${ }^{22}$ samples were not annealed. Thus, the $\mathrm{TiO}_{2}$ layer on Ti samples (P, NT5, and NT20) was still amorphous (therefore, no typical signals were detected by XRD, data not shown). With samples sharing a similar chemical composition (Table 3) and crystal phase, the different cellular responses can be attributed to the impact of surface nanostructures on prepared Ti samples.

In this study, we showed that LS-8 cells were more evenly distributed and produced more pseudopodia on NT5 or NT20 surfaces than on P surface in standard medium. LS-8 cells on NT surfaces proliferated faster, and easily achieved confluence through enhanced interaction (Figures 2A and B, $3 \mathrm{~A}$, and S2). Similar to ameloblasts in the secretory stage, a large number of LS-8 cells facilitated ECM production, aiding the formation of a niche to support their amelogenic differentiation. However, in RA medium, the proliferation of LS-8 cells was significantly suppressed and fewer cells and pseudopodia were observed on all modified Ti surfaces. Moreover, LS-8 cells in six-well culture plates showed a decrease in proliferation, suggesting that the recession of proliferation may be associated with LS- 8 cell maturation with exogenous RA and DEX, independent of different surface chemical compositions ${ }^{44,45}$ and nanostructure.

The proportion of total apoptotic/necrotic cells (Figure 4A) was all increased after $48 \mathrm{~h}$ treatment in RA medium. The expression of $B A X, B C L-2$, and $C A S P 3$ mRNA was upregulated on treatment with RA medium (Figure S3). 


\section{A}
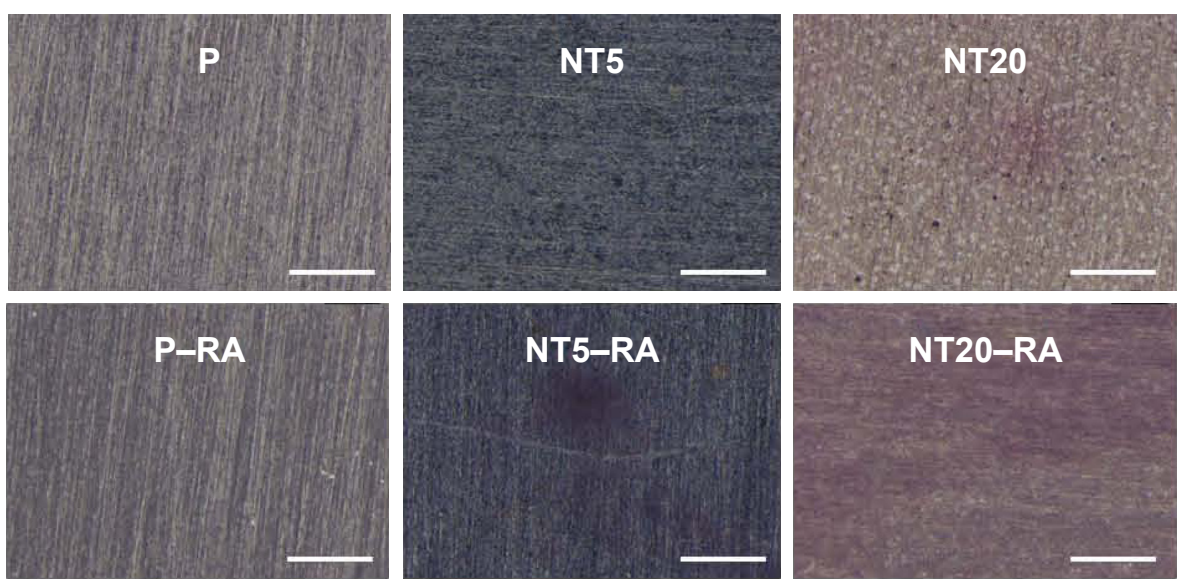

B
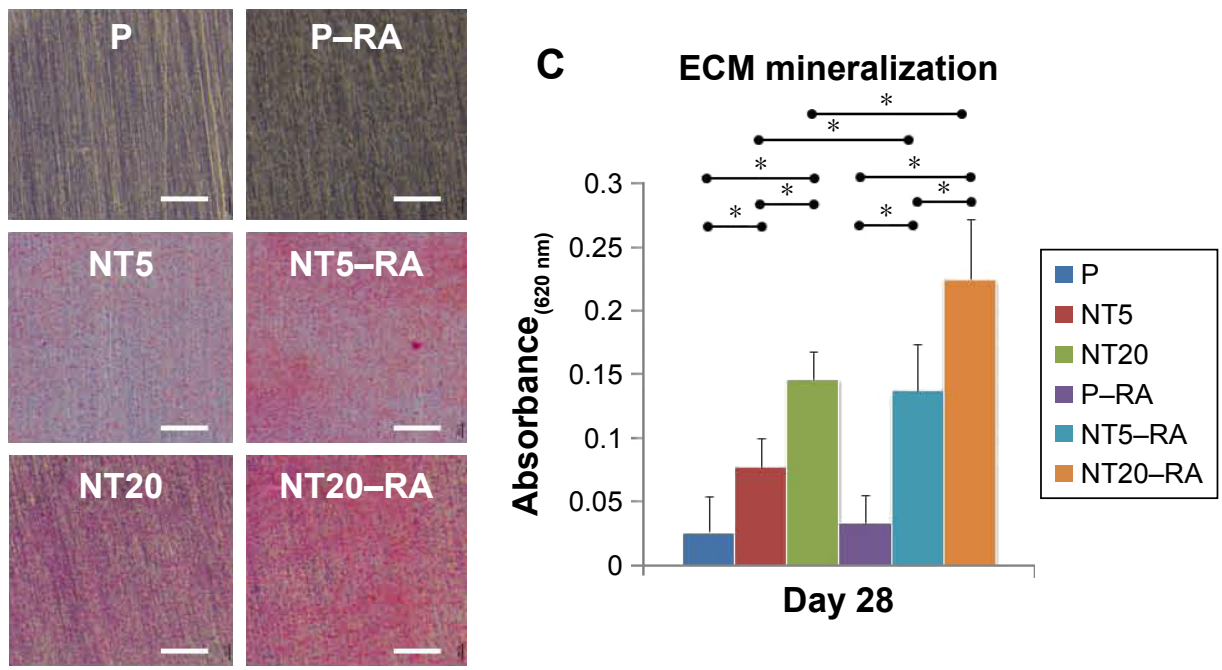

Day 28

Figure 7 Extracellular matrix (ECM) mineralization of LS-8 cells on nanostructured Ti surfaces in standard or RA medium.

Notes: (A) Alkaline phosphatase (ALP) synthesis on modified surfaces in standard medium (upper row) and RA medium (lower row). (B) The formation of mineralized nodules on modified surface in standard medium (left column) and RA medium (right column), with the semi-quantitative analysis (C). Magnification=I00x; scale bar $=400 \mu \mathrm{m}$. $* p<0.01$.

Abbreviation: RA, retinoic acid.

$B A X$ is known to be a component of the intrinsic apoptosis pathway, and $C A S P 3$ is the key executioner of both the intrinsic and extrinsic apoptosis pathways. ${ }^{46-48}$ Higher levels of $B A X$ and $C A S P 3$ mRNA were observed to be associated with increased LS-8 apoptosis/necrosis under RA/DEX stimulation and the upregulated expression of $B C L-2$ (an inhibitor of apoptosis ${ }^{49}$ Figure S3). ${ }^{45}$ Although the mechanism remains controversial, BCL-2 can either elicit or suppress apoptosis according to the status of cellular differentiation. ${ }^{50,51}$ Overexpression of BCL-2 induced osteocyte and bMSC apoptosis during differentiation. ${ }^{52-54}$ Our results are consistent with those of previous studies. ${ }^{45,52-54}$ Thus, BCL-2 may be involved in apoptosis during the amelogenic differentiation of LS-8 cells. However, the role of BAX, BCL-2, and caspase-3 in the apoptosis and amelogenic differentiation of LS-8 cells with RA/DEX stimulation needs further clarification. Intriguingly, the alteration of $B A X, B C L-2$, and $C A S P 3$ expression may be controlled by RA/DEX stimulation directly rather than by the Ti surface nanostructures. At $0 \mathrm{~h}$, the number of viable cells on the NT20 surface exceeded that on the $\mathrm{P}$ and NT5 surfaces, perhaps because the proliferation on the NT20 surface was promoted during the $24 \mathrm{~h}$ pre-culture as described in section 2.4.

In our previous work, $\mathrm{TiO}_{2}$ NT surfaces promoted proliferation, osteogenic gene expression, collagen synthesis, and mineralized nodule formation of osteoblastic lineage cells, including osteoblasts and bMSCs. ${ }^{25,26}$ Ameloblasts are similar to osteoblastic lineage cells in terms of their role in the formation of mineralized tissues. Therefore, we hypothesized that $\mathrm{TiO}_{2}$ NT surfaces may enhance the amelogenic behavior of LS-8 cells. In standard medium, NT5 and NT20 significantly enhanced amelogenic gene expression. However, such promotion was partially altered in the RA medium. Notably, RUNX2, KLK4, and $O D A M$ were 
expressed similarly in standard medium on all Ti surfaces (except $R U N X 2$ at Day 7) but were highly expressed on NT5 and NT20 surfaces with RA/DEX medication. In contrast, the MMP-20 expression was increased on NT5 and NT20 surfaces in standard medium but was suppressed with RA/DEX medication. A similar impact of RA/DEX on the expression of $B M P-2, S H H, A M E L X, A M B N$, and ENAM was also observed on modified Ti surfaces.

BMP-2 and RUNX2 are crucial for various tooth development stages. ${ }^{55}$ BMP-2 is constantly expressed during the differentiation of odontoblasts and ameloblasts in embryonic and postnatal tooth development. ${ }^{56} \mathrm{SHH}$ is another crucial regulator for germ growth/morphogenesis and tissue-tissue interactions that participates in the proliferation and differentiation of dental epithelial stem cells, and controls the fate of dental epithelium as an autocrine signal. ${ }^{56,57}$ Together with SHH, BMP-2/SHH signaling is very important for the fate of dental epithelial stem cells during organogenesis, and partially contributes to the different growth potential of postnatal teeth. ${ }^{58,59}$ On the other hand, RUNX2 is essential for later stages of tooth formation, during the formation of mineralized tooth tissues, and functions as a regulator by binding to the ameloblastin promoter region. ${ }^{60-62}$

The morphological formation of the tooth crown is precisely controlled by a balance of proliferation and differentiation of dental epithelium-derived ameloblasts. ${ }^{63}$ Ameloblasts support and regulate enamel formation by producing enamel organic matrix biomolecules such as amelogenin, ameloblastin, enamelin, and enamel matrix proteases, including KLK4 and MMP-20. ${ }^{64-67}$ Although containing very little protein $(<5 \%)$, enamel matrix proteins are crucial for the formation and maturation of tooth enamel. ${ }^{12}$ Enamel matrix proteins are highly expressed in the secretory stage of enamel development. ${ }^{68}$ In the present study, we analyzed three enamel matrix proteins including amelogenin X-linked (AMELX), ameloblastin $(A M B N)$, and enamelin (ENAM). Amelogenin and enamelin are the two main kinds of protein produced during the development of postnatal enamel in mammals. ${ }^{69}$ Amelogenin is mainly secreted by ameloblasts and regulates the organization of crystallographic structure and thickness of enamel. ${ }^{70}$ Besides, ameloblastin is produced by ameloblasts and comprises $5 \%-10 \%$ of all enamel proteins. Although not fully understood, ameloblastin is thought to be a regulator of enamel crystal elongation and enamel mineralization. ${ }^{71}$ As a cell-adhesion molecule, AMBN is indispensable for the attachment of ameloblasts to the enamel matrix and polarity. ${ }^{14}$

Enamel matrix proteins are secreted by ameloblasts during the secretory stage of amelogenesis and then are decomposed by enamel-specific proteases during the maturation stage. ${ }^{72}$ KLK4 and MMP-20 are the two main enamel-specific proteases that are secreted at different stages of amelogenesis. MMP (a zinc-dependent peptidase) decomposes many ECM proteins, and plays an important role in early amelogenesis. ${ }^{73,74}$ MMP-20 expression is mostly elevated during the late secretory/transitional stages of enamel development and is dramatically decreased during the maturation stage. ${ }^{75}$ KLK4 expression was enhanced in the transition stage and remained elevated during the maturation stage. ${ }^{76}$ The decreased expressions of BMP-2, AMELX, AMBN, ENAM, and $K L K 4$ mRNA and increased expression of RUNX2, SHH, $K L K 4$, and $O D A M$ mRNA suggested that LS-8 cells were differentiated into the maturation stage in the presence of RA medium on P (Figure S4A). ${ }^{28,45}$ Such alteration in the mRNA expression of enamel matrix proteins and proteases has been reported previously by Yang et $\mathrm{a}{ }^{45}$ and Suzawa et al. ${ }^{77}$ Notably, $M M P-20$ expression dropped significantly on treatment with RA medium (Figure S4), which is partially inconsistent with a previous report. ${ }^{45}$ Compared to Yang et al's study, LS-8 cells in this study were cultured for an additional 1 or 5 days after $48 \mathrm{~h}$ treatment with RA/DEX. Therefore, the divergence of $M M P-20$ expression may be attributed to the different maturation stages of ameloblasts.

Besides the regulative effects of RA medium, the surface nanostructure can further manipulate the amelogenic behaviors of ameloblasts. $\mathrm{TiO}_{2}$ NT surfaces, especially NT20 surfaces, improved the amelogenic functions of ameloblasts both in standard and RA media - as confirmed by macroscopic observation of ALP synthesis and mineralized nodule formation (Figure 7). According to the pattern of amelogenic gene expression observed in different culture media, it was clear that the regulatory effect of the $\mathrm{TiO}_{2}$ NT surface was mild and unlikely to directly drive maturation of LS-8 cells. However, the combination of surface nanostructure and short-term RA/DEX medication could promote enamel matrix molecule secretion and maturation of ameloblasts, following enhanced mineralized enamel formation in the macroscopic view without any exogenous mineralization inducer. In addition, the timing and dose of RA/DEX treatment should be carefully determined, as improper or excessive RA/DEX stimulation reduces LS-8 cell viability and even impairs amelogenesis and, thereby, may result in enamel defects in vivo. ${ }^{78}$

Future improvements to our research include methods to fabricate the biomimetic surface nanostructure of biomaterials with additional chemical-biological modifications, to regulate maturation of ameloblasts via precise biomolecules and other bioactive compounds. Furthermore, 
primary dental epithelium and ameloblasts should be employed in further research as they possess the full range of cellular functions.

\section{Conclusion}

Nanotube arrays of various tube sizes and morphological features can be constructed on Ti surfaces via anodization. The surface nanostructures can effectively induce amelogenic differentiation of LS-8 cells. Anodized Ti surfaces may further enhance the amelogenic functions of LS- 8 cells in combination with precise administration of RA/DEX. The current study established a systemic framework suitable for enamel maturation and regeneration based on biomaterial surface nanotopography.

\section{Acknowledgments}

This work was supported financially by the National Natural Science Fund (grant nos. 91442108, 81501599, 81530051, and 81571531 ) and funded by the China Postdoctoral Science Foundation (grant no. 2016M593009). Special thanks to Prof Malcolm L Snead of USC for kindly donating the LS-8 cell line.

\section{Disclosure}

The authors report no conflicts of interest in this work.

\section{References}

1. Petersen PE, Yamamoto T. Improving the oral health of older people: the approach of the WHO Global Oral Health Programme. Community Dent Oral Epidemiol. 2005;33(2):81-92.

2. Baelum V, Fejerskov O. Tooth loss as related to dental caries and periodontal breakdown in adult Tanzanians. Community Dent Oral Epidemiol. 1986;14(6):353-357.

3. Niessen LC, Weyant RJ. Causes of tooth loss in a veteran population. J Public Health Dent. 1989;49(1):19-23.

4. Cooper LF. The current and future treatment of edentulism. JProsthodont. 2009; 18(2):116-122.

5. Ravindran S, George A. Biomimetic extracellular matrix mediated somatic stem cell differentiation: applications in dental pulp tissue regeneration. Front Physiol. 2015;6:118.

6. Monteiro N, Yelick PC. Advances and perspectives in tooth tissue engineering. J Tissue Eng Regen Med. 2017;11(9):2443-2461.

7. Lai WF, Lee JM, Jung HS. Molecular and engineering approaches to regenerate and repair teeth in mammals. Cell Mol Life Sci. 2014;71(9): 1691-1701.

8. Hirayama M, Oshima M, Tsuji T. Development and prospects of organ replacement regenerative therapy. Cornea. 2013;32 Suppl 1: S13-S21.

9. Xu W, Jiang S, Chen Q, et al. Systemically Transplanted Bone Marrowderived Cells Contribute to Dental Pulp Regeneration in a Chimeric Mouse Model. J Endod. 2016;42(2):263-268.

10. Shen JZ, Kosmač T. Advanced Ceramics for Dentistry. Waltham, MA: Elsevier/BH; 2014.

11. Ten Cate AR. Ten Cate's Oral Histology. Oxford: Elsevier; 2013.

12. Nanci A. Ten Cate's Oral Histology: Development, Structure, and Function. Singapore: Elsevier Pte limited; 2013.

13. Zafar MS, Khurshid Z, Almas K. Oral tissue engineering progress and challenges. Tissue Engin Regener Med. 2015;12(6):387-397.
14. Fukumoto S, Kiba T, Hall B, et al. Ameloblastin is a cell adhesion molecule required for maintaining the differentiation state of ameloblasts. J Cell Biol. 2004;167(5):973-983.

15. Zhang YD, Chen Z, Song YQ, Liu C, Chen YP. Making a tooth: growth factors, transcription factors, and stem cells. Cell Res. 2005;15(5): 301-316.

16. Dalby MJ, Gadegaard N, Tare R, et al. The control of human mesenchymal cell differentiation using nanoscale symmetry and disorder. Nat Mater. 2007;6(12):997-1003.

17. Zhao L, Liu L, Wu Z, Zhang Y, Chu PK. Effects of micropitted/ nanotubular titania topographies on bone mesenchymal stem cell osteogenic differentiation. Biomaterials. 2012;33(9):2629-2641.

18. Schwartz Z, Lohmann CH, Sisk M, et al. Local factor production by MG63 osteoblast-like cells in response to surface roughness and $1,25-(\mathrm{OH}) 2 \mathrm{D} 3$ is mediated via protein kinase $\mathrm{C}$ - and protein kinase A-dependent pathways. Biomaterials. 2001;22(7):731-741.

19. Wang $\mathrm{W}$, Zhao $\mathrm{L}, \mathrm{Wu} \mathrm{K}$, et al. The role of integrin-linked kinase/ $\beta$-catenin pathway in the enhanced MG63 differentiation by micro/ nano-textured topography. Biomaterials. 2013;34(3):631-640.

20. Zhao L, Mei S, Chu PK, Zhang Y, Wu Z. The influence of hierarchical hybrid micro/nano-textured titanium surface with titania nanotubes on osteoblast functions. Biomaterials. 2010;31(19):5072-5082.

21. Tzaphlidou M. The role of collagen in bone structure: an image processing approach. Micron. 2005;36(7-8):593-601.

22. Mei S, Zhao L, Wang W, Ma Q, Zhang Y. Biomimetic titanium alloy with sparsely distributed nanotubes could enhance osteoblast functions. Adv Eng Mater. 2012;14(4):B166-B174.

23. Yilmaz ED, Schneider GA. Mechanical behavior of enamel rods under micro-compression. J Mech Behav Biomed Mater. 2016;63:183-194.

24. Ma Q, Wang W, Chu PK, et al. Concentration- and time-dependent response of human gingival fibroblasts to fibroblast growth factor 2 immobilized on titanium dental implants. Int J Nanomedicine. 2012;7: 1965-1976.

25. Ma QL, Zhao LZ, Liu RR, et al. Improved implant osseointegration of a nanostructured titanium surface via mediation of macrophage polarization. Biomaterials. 2014;35(37):9853-9867.

26. Wang W, Zhao L, Ma Q, Wang Q, Chu PK, Zhang Y. The role of the Wnt/ $\beta$-catenin pathway in the effect of implant topography on MG63 differentiation. Biomaterials. 2012;33(32):7993-8002.

27. Chen LS, Couwenhoven RI, Hsu D, Luo W, Snead ML. Maintenance of amelogenin gene expression by transformed epithelial cells of mouse enamel organ. Arch Oral Biol. 1992;37(10):771-778.

28. Sarkar J, Simanian EJ, Tuggy SY, et al. Comparison of two mouse ameloblast-like cell lines for enamel-specific gene expression. Front Physiol. 2014;5:277.

29. Khang D, Lu J, Yao C, Haberstroh KM, Webster TJ. The role of nanometer and sub-micron surface features on vascular and bone cell adhesion on titanium. Biomaterials. 2008;29(8):970-983.

30. Webster TJ, Schadler LS, Siegel RW, Bizios R. Mechanisms of enhanced osteoblast adhesion on nanophase alumina involve vitronectin. Tissue Eng. 2001;7(3):291-301.

31. Khang D, Kim SY, Liu-Snyder P, Palmore GT, Durbin SM, Webster TJ. Enhanced fibronectin adsorption on carbon nanotube/poly(carbonate) urethane: independent role of surface nano-roughness and associated surface energy. Biomaterials. 2007;28(32):4756-4768.

32. Gong D, Grimes CA, Varghese OK, et al. Titanium oxide nanotube arrays prepared by anodic oxidation. J Mater Res. 2001;16(12):3331-3334.

33. Nel AE, Mädler L, Velegol D, et al. Understanding biophysicochemical interactions at the nano-bio interface. Nat Mater. 2009;8(7):543-557.

34. Zafar M, Najeeb S, Khurshid Z, et al. Potential of electrospun nanofibers for biomedical and dental applications. Materials. 2016;9(2):73.

35. Heydarkhan-Hagvall S, Choi CH, Dunn J, et al. Influence of systematically varied nano-scale topography on cell morphology and adhesion. Cell Commun Adhes. 2007;14(5):181-194.

36. Yim EK, Darling EM, Kulangara K, Guilak F, Leong KW. Nanotopography-induced changes in focal adhesions, cytoskeletal organization, and mechanical properties of human mesenchymal stem cells. Biomaterials. 2010;31(6):1299-1306. 
37. Oh S, Brammer KS, Li YS, et al. Stem cell fate dictated solely by altered nanotube dimension. Proc Natl Acad Sci U S A. 2009;106(7): 2130-2135.

38. Guvendiren M, Burdick JA. The control of stem cell morphology and differentiation by hydrogel surface wrinkles. Biomaterials. 2010; 31(25):6511-6518.

39. Laxman B, Hall DE, Bhojani MS, et al. Noninvasive real-time imaging of apoptosis. Proc Natl Acad Sci U S A. 2002;99(26):16551-16555.

40. Lee S, Choi J, Shin S, et al. Analysis on migration and activation of live macrophages on transparent flat and nanostructured titanium. Acta Biomater. 2011;7(5):2337-2344.

41. Trinchieri G, Sher A. Cooperation of Toll-like receptor signals in innate immune defence. Nat Rev Immunol. 2007;7(3):179-190.

42. Khandwekar A, Rho CK. Modulation of cellular responses on engineered polyurethane implants. J Biomed Mater Res A. 2012;100(9): 2211-2222.

43. Ivanovski S, Hamlet S, Salvi GE, et al. Transcriptional profiling of osseointegration in humans. Clin Oral Implants Res. 2011;22(4): 373-381.

44. Yang T, Zhang Y, Zheng D, Hao Y, Snead ML, Duan X. High-fluoride promoted phagocytosis-induced apoptosis in a matured ameloblast-like cell line. Arch Oral Biol. 2015;60(1):84-90.

45. Yang T, Zhang Y, Li Y, et al. High amounts of fluoride induce apoptosis/cell death in matured ameloblast-like LS8 cells by downregulating Bcl-2. Arch Oral Biol. 2013;58(9):1165-1173.

46. Kole AJ, Knight ER, Deshmukh M. Activation of apoptosis by cytoplasmic microinjection of cytochrome c. J Vis Exp. 2011;(52). pii: 2773.

47. Tait SW, Green DR. Mitochondrial regulation of cell death. Cold Spring Harb Perspect Biol. 2013;5(9). pii: a008706.

48. Shamas-Din A, Bindner S, Zhu W, et al. tBid undergoes multiple conformational changes at the membrane required for Bax activation. J Biol Chem. 2013;288(30):22111-22127.

49. Nie H, Rathbun G, Tucker H. Smyd1C mediates CD8 T cell death via regulation of $\mathrm{Bcl} 2$-mediated restriction of outer mitochondrial membrane integrity. J Cell Signal. 2017;2(3). pii: 163.

50. Hoffman B, Liebermann DA. Apoptotic signaling by c-MYC. Oncogene. 2008;27(50):6462-6472.

51. Desagher S, Martinou JC. Mitochondria as the central control point of apoptosis. Trends Cell Biol. 2000;10(9):369-377.

52. Nagase Y, Iwasawa M, Akiyama T, et al. Anti-apoptotic molecule Bcl-2 regulates the differentiation, activation, and survival of both osteoblasts and osteoclasts. J Biol Chem. 2009;284(52):36659-36669.

53. Moriishi T, Maruyama Z, Fukuyama R, et al. Overexpression of Bcl2 in osteoblasts inhibits osteoblast differentiation and induces osteocyte apoptosis. PLoS One. 2011;6(11):e27487.

54. Oliver L, Hue E, Rossignol J, et al. Distinct roles of Bcl-2 and Bcl-Xl in the apoptosis of human bone marrow mesenchymal stem cells during differentiation. PLoS One. 2011;6(5):e19820.

55. Tummers M, Thesleff I. The importance of signal pathway modulation in all aspects of tooth development. J Exp Zool B Mol Dev Evol. 2009;312B(4):309-319.

56. Liu G, Ma S, Zhou Y, et al. Signaling pathways in dental stem cells during their maintenance and differentiation. In: Şahin F, Doğan A, Demirci S, editors. Dental Stem Cells. Cham: Springer International Publishing; 2016:69-92.

57. Wu C, Shimo T, Liu M, Pacifici M, Koyama E. Sonic hedgehog functions as a mitogen during bell stage of odontogenesis. Connect Tissue Res. 2003;44 Suppl 1:92-96.

58. Li J, Feng J, Liu Y, et al. BMP-SHH signaling network controls epithelial stem cell fate via regulation of its niche in the developing tooth. Dev Cell. 2015;33(2):125-135.
59. Monteiro N, Smith EE, Angstadt S, Zhang W, Khademhosseini A, Yelick PC. Dental cell sheet biomimetic tooth bud model. Biomaterials. 2016;106:167-179.

60. Du J, Wang Q, Yang P, Wang X. FHL2 mediates tooth development and human dental pulp cell differentiation into odontoblasts, partially by interacting with Runx2. J Mol Histol. 2016;47(2):195-202.

61. Camilleri S, McDonald F. Runx2 and dental development. Eur J Oral Sci. 2006;114(5):361-373.

62. Dhamija S, Liu Y, Yamada Y, Snead ML, Krebsbach PH. Cloning and characterization of the murine ameloblastin promoter. J Biol Chem. 1999;274(29):20738-20743.

63. Dassule HR, Lewis P, Bei M, Maas R, McMahon AP. Sonic hedgehog regulates growth and morphogenesis of the tooth. Development. 2000;127(22):4775-4785.

64. Hu CC, Fukae M, Uchida T, et al. Cloning and characterization of porcine enamelin mRNAs. J Dent Res. 1997;76(11):1720-1729.

65. Krebsbach PH, Lee SK, Matsuki Y, Kozak CA, Yamada KM, Yamada Y. Full-length sequence, localization, and chromosomal mapping of ameloblastin. A novel tooth-specific gene. J Biol Chem. 1996;271(8): 4431-4435.

66. Llano E, Pendás AM, Knäuper V, et al. Identification and structural and functional characterization of human enamelysin (MMP-20). Biochemistry. 1997;36(49):15101-15108.

67. Nelson PS, Gan L, Ferguson C, et al. Molecular cloning and characterization of prostase, an androgen-regulated serine protease with prostate-restricted expression. Proc Natl Acad Sci U S A. 1999;96(6): 3114-3119.

68. Simmer JP, Fincham AG. Molecular mechanisms of dental enamel formation. Crit Rev Oral Biol Med. 1995;6(2):84-108.

69. Hu JC, Yamakoshi Y. Enamelin and autosomal-dominant amelogenesis imperfecta. Crit Rev Oral Biol Med. 2003;14(6):387-398.

70. Xu L, Harada H, Yokohama-Tamaki T, Matsumoto S, Tanaka J, Taniguchi A. Reuptake of extracellular amelogenin by dental epithelial cells results in increased levels of amelogenin mRNA through enhanced mRNA stabilization. J Biol Chem. 2006;281(4):2257-2262.

71. Hu JC, Chun YH, Al Hazzazzi T, Simmer JP. Enamel formation and amelogenesis imperfecta. Cells Tissues Organs. 2007;186(1):78-85.

72. Bartlett JD, Simmer JP. Proteinases in developing dental enamel. Crit Rev Oral Biol Med. 1999;10(4):425-441.

73. Shintani S, Kobata M, Kamakura N, Toyosawa S, Ooshima T. Identification and characterization of matrix metalloproteinase-20 (MMP20; enamelysin) genes in reptile and amphibian. Gene. 2007; 392(1-2):89-97.

74. Sulkala M, Larmas M, Sorsa T, Salo T, Tjäderhane L. The localization of matrix metalloproteinase-20 (MMP-20, enamelysin) in mature human teeth. J Dent Res. 2002;81(9):603-607.

75. Bartlett JD, Ryu OH, Xue J, Simmer JP, Margolis HC. Enamelysin mRNA displays a developmentally defined pattern of expression and encodes a protein which degrades amelogenin. Connect Tissue Res. 1998;39(1-3):101-109; discussion 141-149.

76. Overall CM, Limeback H. Identification and characterization of enamel proteinases isolated from developing enamel. Amelogeninolytic serine proteinases are associated with enamel maturation in pig. Biochem J. 1988;256(3):965-972.

77. Suzawa T, Itoh N, Takahashi N, et al. Establishment of primary cultures for mouse ameloblasts as a model of their lifetime. Biochem Biophys Res Commun. 2006;345(3):1247-1253.

78. Morkmued S, Laugel-Haushalter V, Mathieu E, et al. Retinoic acid excess impairs amelogenesis inducing enamel defects. Front Physiol. 2017;7:673. 


\section{Supplementary materials}
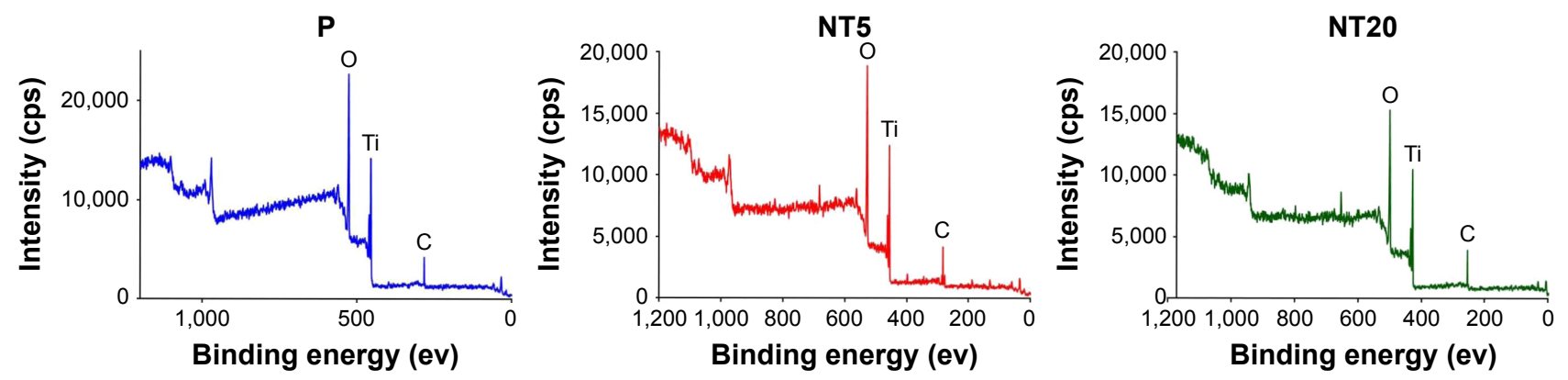

Figure SI Elements analysis on nanostructured Ti surfaces via X-ray photoelectron spectroscopy (XPS) scanning. Abbreviation: CPS, counts per second; ev, electron volt.

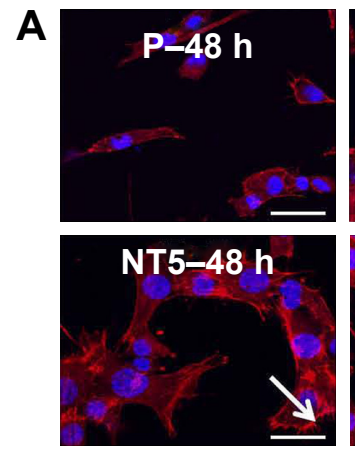

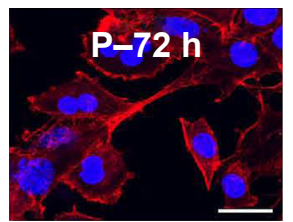

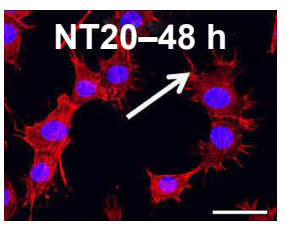

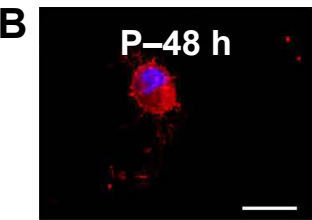

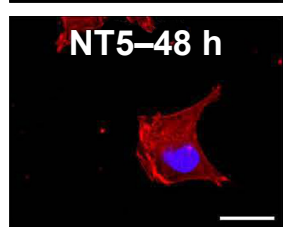

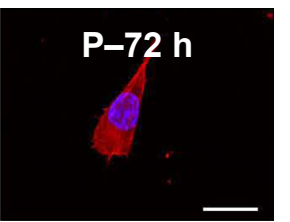

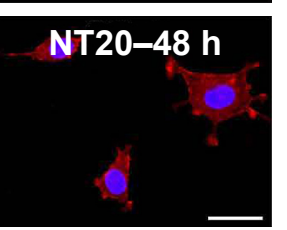

Figure S2 Morphology of LS-8 cells cultured on nanostructured Ti surfaces in standard medium (A) and RA medium (B), the arrows indicate pseudopods of LS-8 cells. Magnification $=400 \times$; scale bar $=25 \mu \mathrm{m}$.

Abbreviation: RA, retinoic acid; $P$, polished Ti surface.
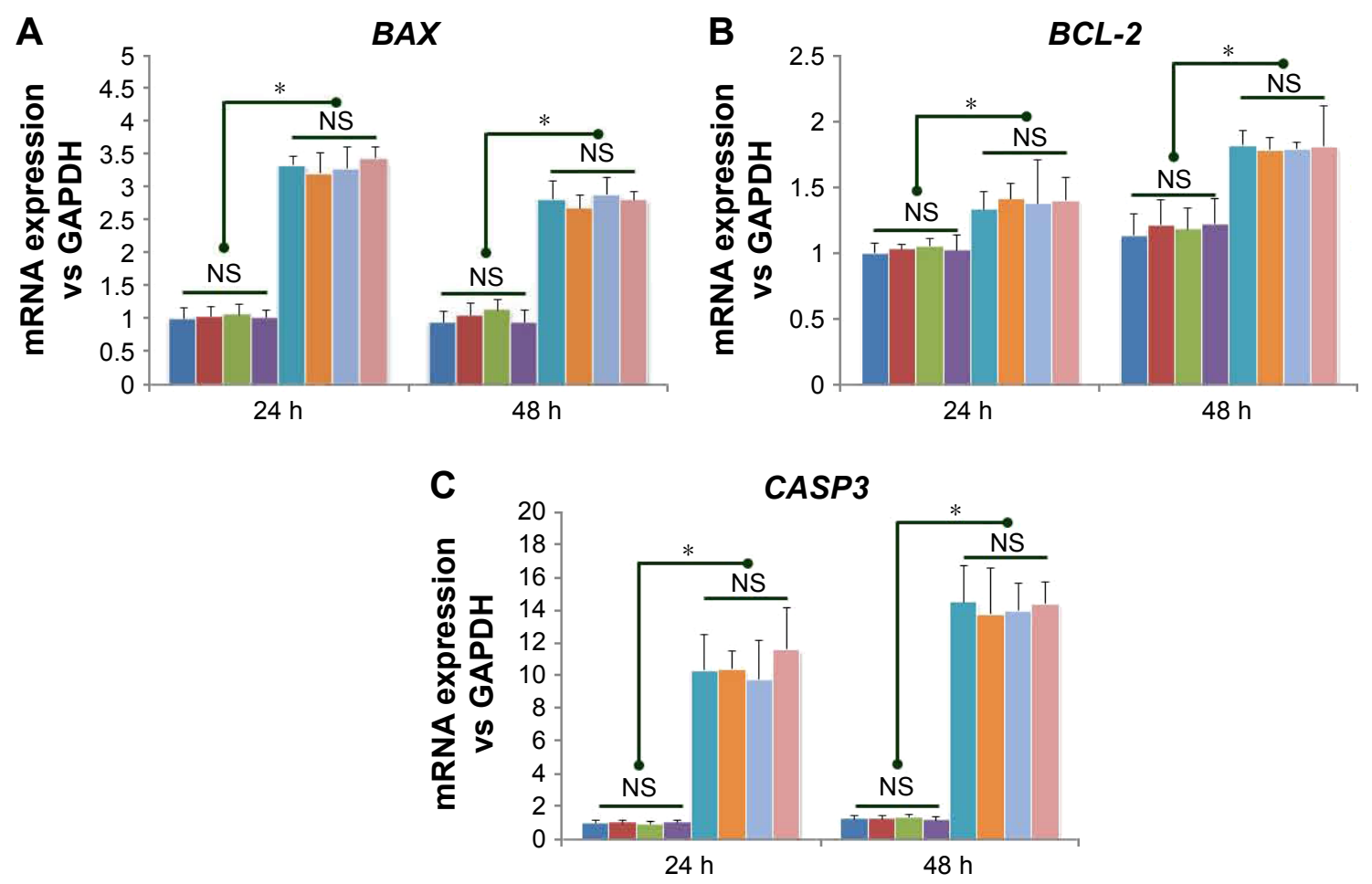

$=\mathrm{P}=\mathrm{NT5}-\mathrm{NT20}=\mathrm{CP}=\mathrm{P}-\mathrm{RA}=\mathrm{NT5}-\mathrm{RA}=\mathrm{NT20-RA}=\mathrm{CP}-\mathrm{RA}$

Figure S3 The apoptosis-related genes expression of LS-8 cells on nanostructured Ti surfaces in standard medium and RA medium at 24 and $48 \mathrm{~h}$. (A) BAX, (B) BCL-2, and (C) CASP3. ${ }^{*}<0.01$.

Abbreviation: NS, no significance. 
A

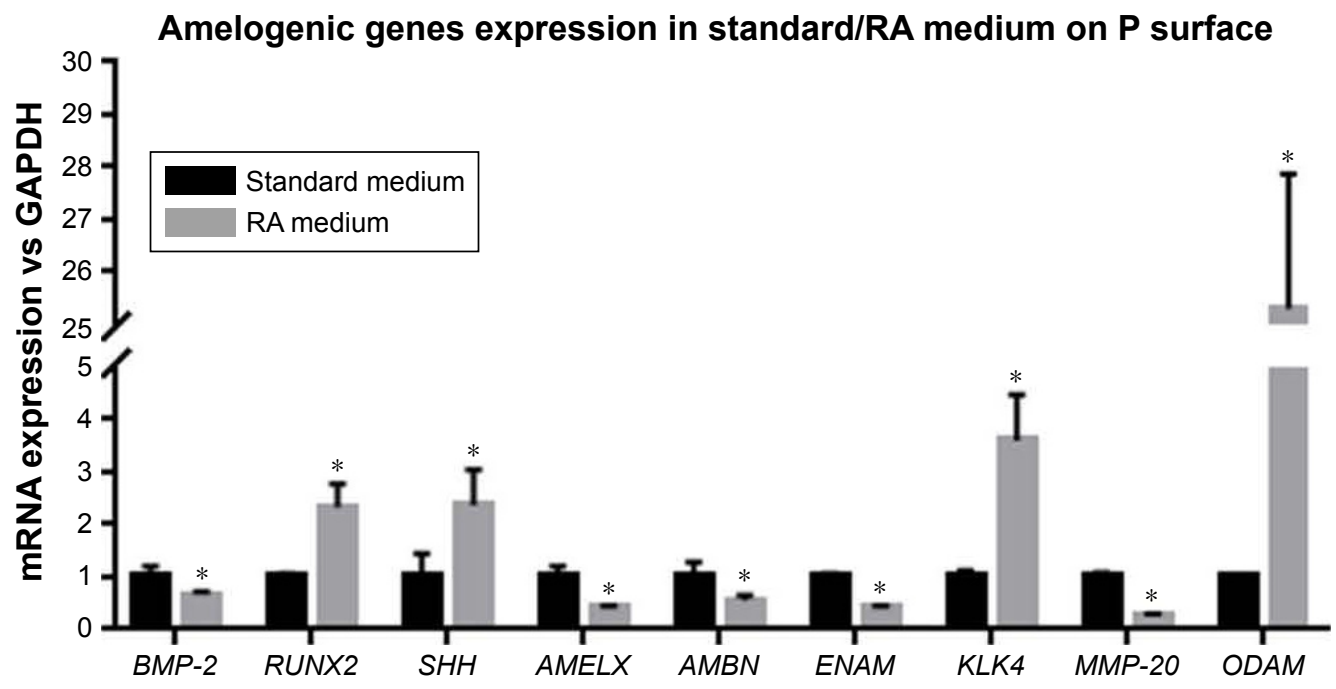

B

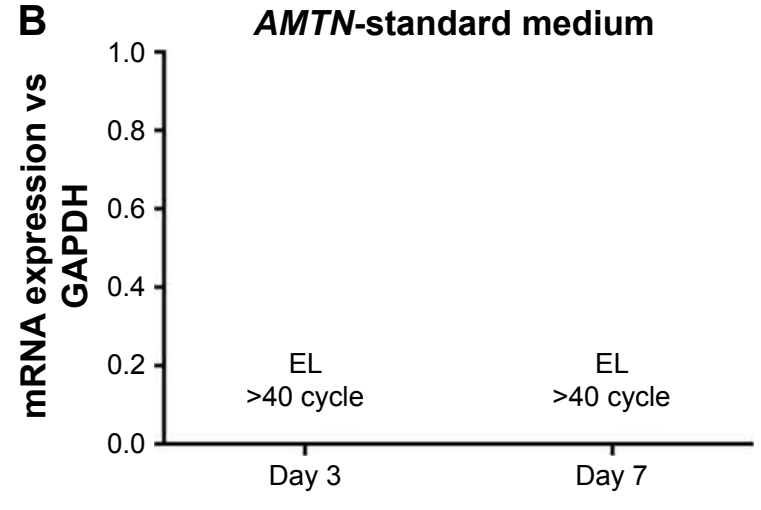

C

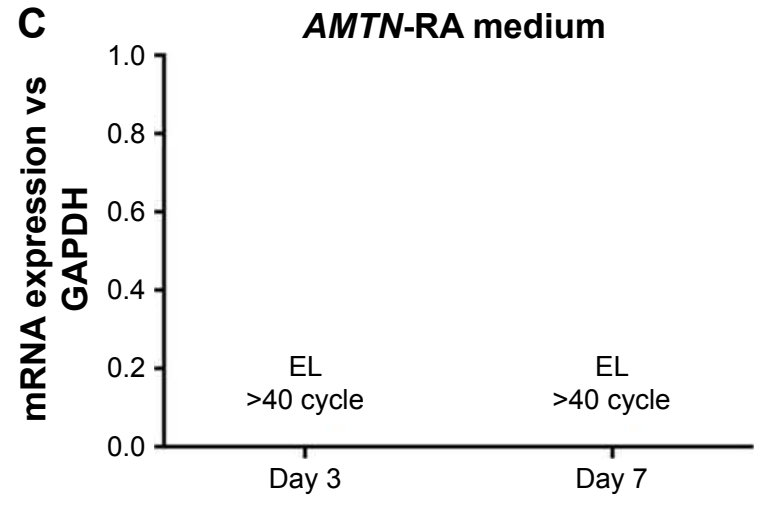

\begin{tabular}{l|l|}
\hline P & NT5
\end{tabular}

Figure S4 The alternation of amelogenic genes expression in LS-8 cells in response to RA medium 48-h pretreatment: (A) amelogenic genes expression on polished Ti surface in presence/absence of RA medium. (B) AMTN expression on nanostructured Ti surfaces in standard medium. (C) AMTN expression on nanostructured Ti surfaces with RA medium pretreatment. $* p<0.0$ I.

Abbreviations: EL, extremely low level; RA, retinoic acid.

\section{Publish your work in this journal}

The International Journal of Nanomedicine is an international, peerreviewed journal focusing on the application of nanotechnology in diagnostics, therapeutics, and drug delivery systems throughout the biomedical field. This journal is indexed on PubMed Central, MedLine, CAS, SciSearch $®$, Current Contents ${ }^{\circledR} /$ Clinical Medicine,
Journal Citation Reports/Science Edition, EMBase, Scopus and the Elsevier Bibliographic databases. The manuscript management system is completely online and includes a very quick and fair peer-review system, which is all easy to use. Visit http://www.dovepress.com/ testimonials.php to read real quotes from published authors. 